EUROPEAN CENTRAL BANK

WORKING PAPER SERIES

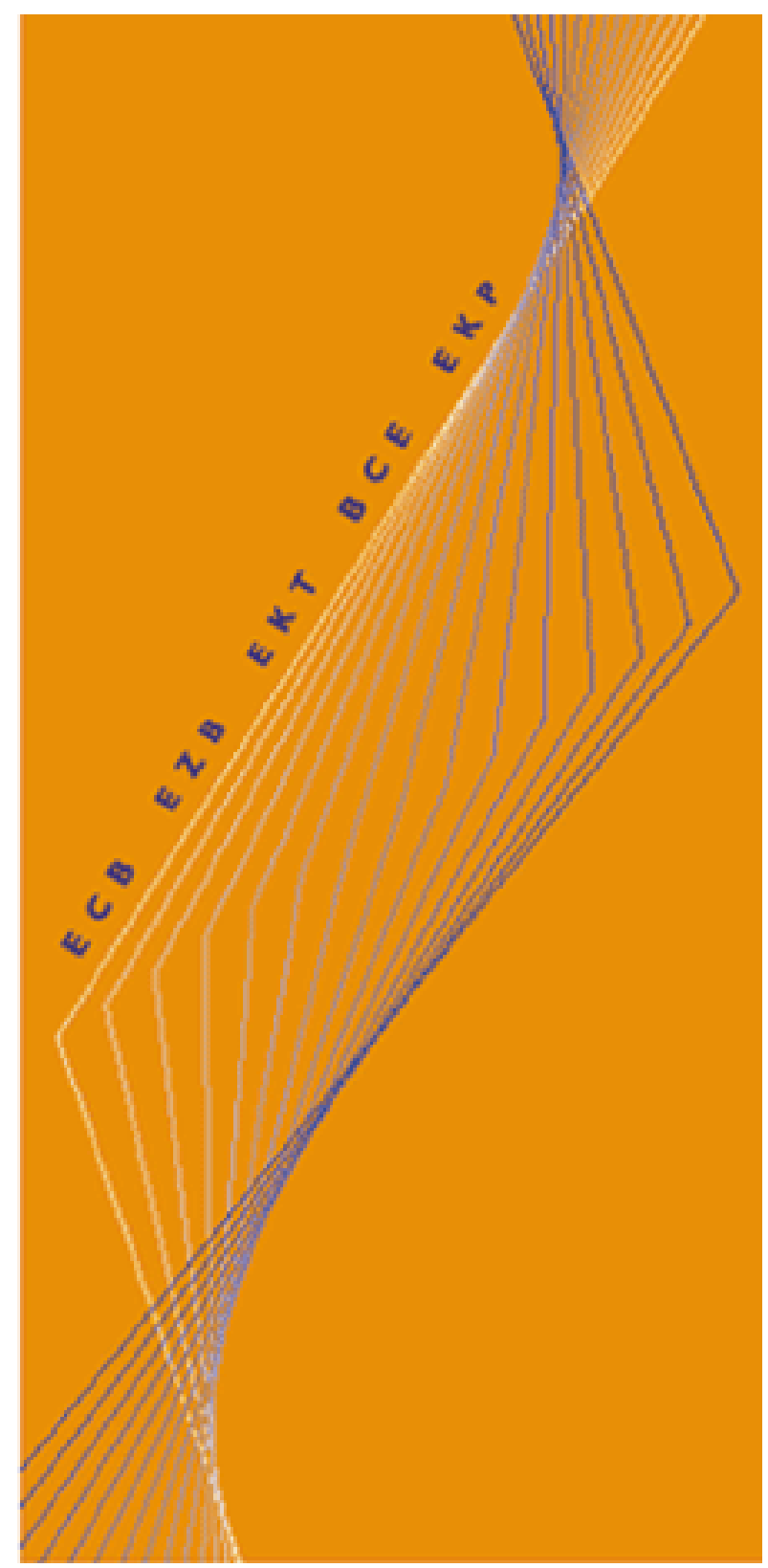

WORKING PAPER NO. 244

HOW DOES THE ECB ALLOT LIQUIDITY IN ITS WEEKLY

MAIN REFINANCING OPERATIONS? A LOOK AT THE EMPIRICAL EVIDENCE

BY STEEN EJERSKOV, CLARA MARTIN MOSS AND LIVIO STRACCA

July 2003 


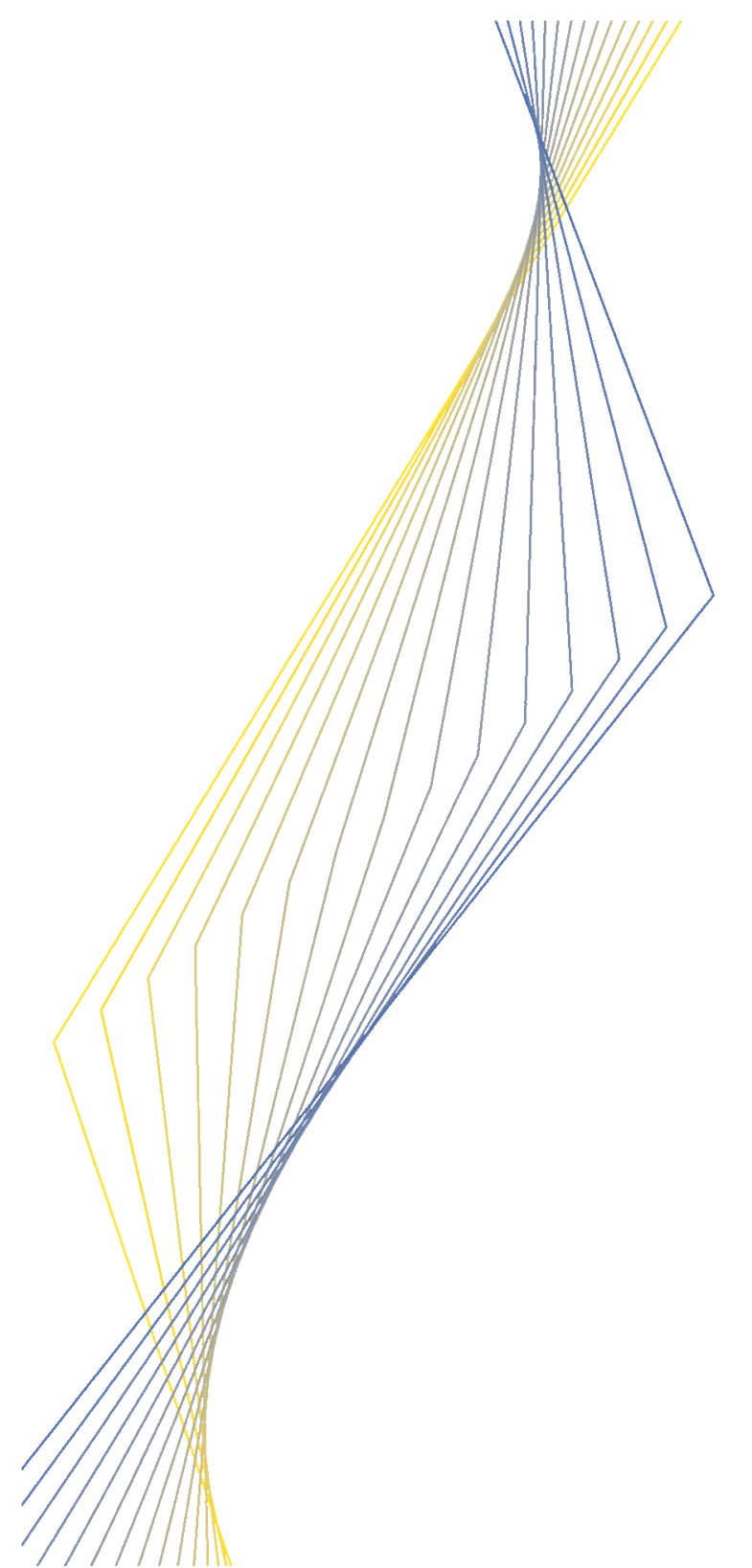

WORKING PAPER NO. 244

HOW DOES THE ECB ALLOT

LIQUIDITY IN ITS WEEKLY

MAIN REFINANCING

OPERATIONS? A LOOK AT

THE EMPIRICAL EVIDENCE'

BY STEEN EJERSKOV', CLARA MARTIN MOSS ${ }^{2}$ AND LIVIO STRACCA ${ }^{2}$

\section{July 2003}

I We thank Ignazio Angeloni, Ulrich Bindseil, Francesco Drudi, José Luis Escrivà, Vítor Gaspar, Hans-Joachim Klöckers, Athanasios Orphanides, Francesco Papadia, Franz Seitz, Flemming Würtz, an anonymous referee and especially Nuno Cassola for useful suggestions as well as participants in an internal seminar at the ECB for comments. The opinions expressed herein are those of the author(s) and do not necessarily represent those of the European Central Bank. This paper can be downloaded without charge from http://www.ecb. int or from the Social Science Research Network electronic library at: http://ssrn.com/abstract_id=4573 I 6.

2 European Central Bank, Kaiserstrasse 29,603II Frankfurt am Main, Germany. E-mail correspondence to steen.ejerskov@ecb.int or livio.stracca@ecb.int. 
(C) European Central Bank, 2003

$\begin{array}{ll}\text { Address } & \text { Kaiserstrasse 29 } \\ & \text { D-603 I I Frankfurt am Main } \\ & \text { Germany } \\ & \text { Postfach } 1603 \text { I9 } \\ \text { Postal address } & \text { Germany Frankfurt am Main } \\ & +4969 \text { I344 } 0 \\ \text { Telephone } & \text { http://www.ecb.int } \\ \text { Internet } & +4969 \text { I344 } 6000 \\ \text { Fax } & 41 \text { I I44 ecb d } \\ \text { Telex } & \end{array}$

All rights reserved by the author/s.

Reproduction for educational and non-commercial purposes is permitted provided that the source is acknowledged. The views expressed in this paper do not necessarily reflect those of the European Central Bank.

ISSN I56I-08I0 (print)

ISSN I725-2806 (online) 


\section{Contents}

$\begin{array}{ll}\text { Abstract } & 4\end{array}$

Non-technical summary $\quad 5$

$\begin{array}{lll}\text { I Introduction } & 7\end{array}$

2 The empirical model 9

2.I The excess demand for liquidity and the overnight rate 10

2.2 The supply of liquidity in the MROs 15

2.2.I The regular supply of liquidity and the "liquidity situation" in the euro area $\quad 15$

2.2.2 A liquidity reaction function for the central bank $\quad 17$

3 The empirical evidence 21

3.I The data 2I

3.2 Estimation and results 27

3.2.I The excess demand for liquidity 27

3.2.2 The supply of liquidity 32

$4 \quad$ Discussion of the results 36

5 Conclusions 38

$\begin{array}{ll}\text { References } & 40\end{array}$

$\begin{array}{ll}\text { Annexes } & 42\end{array}$

European Central Bank working paper series $\quad 48$ 


\begin{abstract}
This paper provides a simple weekly model of the regular supply of liquidity in the euro area, with a view to understanding the functioning of the euro area money market. The main result of the analysis is that liquidity has normally been provided by the ECB in a neutral and smooth manner, but also that there has been some attempt, albeit very limited, to correct deviations of the overnight rate from the main refinancing rate. Moreover, the paper finds that liquidity has affected the overnight interest rate to a significant extent only after the last main refinancing operation of the maintenance period, when it is not possible for the ECB to adjust liquidity imbalances except by making recourse to fine-tuning operations.
\end{abstract}

JEL classification: E52; E43; G21.

Keywords: Bank reserves; monetary policy; martingale hypothesis; liquidity effect; liquidity policy. 


\section{Non-technical summary}

The paper takes a closer look at the regular weekly supply of central bank reserves in the euro area. In particular, we estimate a "liquidity reaction function" for the ECB, which links the provision of liquidity to the level of the overnight rate in the euro area, or other very short-term interest rate indicators, and to special situations which occurred during the sample period (August 1999 to November 2002). We also present a weekly demand model, which may be thought of as the relevant constraint for the central bank's weekly supply decisions. In line with the literature, the demand model relates short-term interest rates to the prevailing liquidity situation. The way we carry out the weekly aggregation of the daily data allows us to identify demand and supply in the empirical model.

The paper reaches the following conclusions. First, from the supply side we find that the ECB has generally provided liquidity in a neutral and smooth way during our sample period, apart from some special circumstances such as the underbidding episodes which occurred four times in 2001. Moreover, it appears that there was also some reaction, albeit limited, to the deviation of the short-term spot and forward interest rates from the main refinancing rate. In particular, if the overnight rate was above the main refinancing rate, primarily reflecting expectations of a change in the main refinancing rate during the same maintenance period, the liquidity allotment has sometimes been slightly loose, and vice versa. However, in light of the results of the demand side of the model, the reaction to interest rate change expectations prevailing in the maintenance period has been very small. This appears to indicate that, in the sample period, a large weight in the ECB liquidity management's loss function was attributed to providing liquidity in a smooth and neutral manner, whereas short-term fluctuations in the EONIA and other very short-term rates did not lead to adjustments in liquidity policy. 
This might be seen as being consistent with a scheme in which the overnight rate is not a direct policy objective, unlike the case for the federal funds rate in the US.

In interpreting this result, it should be noted that the environment of orderly conditions in the money market, which generally prevailed during the first four years of the Economic and Monetary Union (EMU) may also have worked against a very active liquidity policy. In fact, if there are no strong expectations of a change in the main refinancing rate within the maintenance period, there is no trade-off between liquidity and interest rate smoothing. In addition, the result may also suggest that the operational framework of the ECB has worked satisfactorily in keeping the EONIA close to the main refinancing rate without the need for a more active liquidity policy.

Second, from a demand perspective the analysis in this paper finds that the liquidity situation appears to have mattered to a significant extent only in the last week of the maintenance period, after the last main refinancing operation of the period, and to have had a negligible effect earlier in the maintenance period. This finding presumably reflects both the structural features of the euro area money market, in particular the high level of the reserve requirement, and market participants' perception that the ECB's liquidity policy is generally neutral at the end of the maintenance period. This result also suggests that the reserve requirement and the averaging mechanism work effectively in the euro area to contain the volatility of the very short-term rates in response to liquidity shocks. 


\section{Introduction}

The newly established euro area money market has attracted some attention in the literature in recent years (Hartmann, Manna and Manzanares, 2001; Bindseil and Seitz, 2001; Bartolini, Bertola and Prati, 2002; Würtz, 2003). While some of the features of the euro area money market are close to those of the US market, for example the need for banks to fulfil a reserve requirement over a maintenance period and the presence of an averaging mechanism, there are also aspects of the euro market which depart from the US experience studied extensively in the literature (Perez Quiros and Mendizabal, 2001). For example, fluctuations in the overnight rate in the euro area have been limited within the corridor between the rate on the marginal lending facility and that on the deposit facility. Moreover, while the federal funds rate is an explicit target for the US Federal Reserve and has an important signalling role, supported by daily open market operations, in the euro area the overnight rate is not a policy rate and signalling is achieved mainly through the main refinancing rate and the associated corridor between the rates on the standing facilities. ${ }^{1}$ These original features may make it worthwhile to study the euro area money market in more detail.

Recent papers on the euro area money market have tended to focus on the demand side of the market. This paper takes a closer look at the supply side of the market, in the same spirit of the studies by Feinman (1993) and Taylor (2001) for the US. In particular, we look at the regular provision of liquidity in the euro area on a weekly basis. We also present a weekly demand model which may be thought of as the relevant constraint for the central bank's weekly supply of liquidity. By presenting a simple model of supply and demand of liquidity in the euro area, this paper is closest in spirit especially to Taylor's (2001) paper. The supply equation, a "liquidity reaction function" for the ECB, links the provision of liquidity to the level of the EONIA spread or other very short-term interest rate indicators and to special situations which occurred during the considered sample period. ${ }^{2}$ It should be noted that our analysis is descriptive in nature and does not claim to identify the ECB's liquidity reaction function which would have prevailed under conditions different from those which occurred during our sample period, nor the liquidity

\footnotetext{
${ }^{1}$ In our sample period from mid 1999 until November 2002 the main refinancing rate was always at the middle of the corridor between the marginal lending rate and the deposit rate.

${ }^{2}$ Commercial banks "liquidity" and "reserves" (or "reserve holdings") are used interchangably in the paper. It refers to money held at current accounts with the Eurosystem national central banks. The EONIA is a transaction-weighted daily average of the overnight rate in the euro area.
} 
policy which would necessarily prevail in the future. The demand model in the paper relates the spread between the overnight rate in the euro area and the main refinancing rate to the prevailing liquidity situation, defined as the average daily reserve surplus accumulated from the beginning of the maintenance period, excluding recourse to the standing facilities (non-borrowed reserves).

The econometric analysis in the paper, based on weekly data from mid-1999 to November 2002, reveals two interesting features. First, we find that the ECB has generally provided liquidity in a neutral and smooth way during our sample period, apart from some special circumstances such as the underbidding episodes which occurred four times in 2001. Moreover, it appears that there was also some reaction, albeit limited, to the deviation of the EONIA and other short-term spot and forward interest rates from the main refinancing rate. In particular, if the overnight rate, or other very short-term rates, were above the main refinancing rate, primarily reflecting expectations of a change in the main refinancing rate during the same maintenance period, the liquidity allotment has sometimes been slightly loose, and vice versa. However, in light of the results of the demand side of the model, the reaction to deviations of short-term rates from the main refinancing rate has been very small. This appears to indicate that, in the sample period, a large weight in the ECB liquidity management's loss function was attributed to providing liquidity in a smooth and neutral manner, whereas shortterm fluctuations in the EONIA and other very short-term rates did not lead to adjustments in liquidity policy. Prima facie, this might be seen as being consistent with a scheme between the "dealing rate model" and "open mouth approach" (Manna, Pill and Quiros, 2001), or a "handsoff approach" (Bartolini and Prati, 2003), in which the overnight rate is not a policy objective, unlike the case for the federal funds rate in the US. At the same time, it should be noted that the environment of orderly conditions in the money market which generally prevailed during the first four years of EMU may have also worked against an active liquidity policy. In fact, if there are no strong expectations of a change in the main refinancing rate within the maintenance period, there is no trade-off between liquidity and interest rate smoothing. ${ }^{3}$

Second, as regards the demand side, we find that liquidity imbalances have affected the overnight rate only in the last week of the maintenance period, when the ECB cannot correct them unless by making recourse to a fine-tuning operation, which are used very seldom. Reserve require-

\footnotetext{
${ }^{3}$ It should be noted that this distinguishes our analysis from the strand of literature on whether the central bank should target the monetary base or interest rates. On this conceptual difference, see Gilchrist (2001).
} 
ments are binding on the last day of the maintenance period in the euro area (there are no carry-over provisions) and the demand curve becomes vertical. Before the last main refinancing operation (MRO) of the maintenance period, liquidity imbalances affect the EONIA spread only to a very small extent, indicating that there is practically no "liquidity effect" in the euro area apart from the very last days of the period (see Hamilton, 1996, and Thornton, 2001a and 2001b, for opposite views in the US case). ${ }^{4}$ We interpret this result as indicating that the liquidity services provided by a marginal unit of reserves are close to zero with the reserve requirement in place in the euro area; intermediaries hold reserves practically only in order to satisfy the reserve requirement. The results also suggest that the reserve requirement and the averaging mechanism work effectively in the euro area to contain the volatility of the very short-term rates in response to liquidity shocks.

The paper is structured as follows. Section 2 presents the underpinnings of the weekly demand and supply model which is then estimated in Section 3. Section 4 provides some discussion on the results of the analysis. Section 5 concludes.

\section{The empirical model}

The main purpose of the empirical model proposed in this paper is to establish a simple representation of the main features of the demand for and supply of reserves in the euro area. The focus of the analysis is in particular on the supply of reserves by the ECB, while demand acts as a constraint on central bank behaviour and is an important element in assessing the ECB's supply policy from a welfare perspective. The focus on simplicity prevents the model from providing the best ex post possible account of the considered variables (reserves and the overnight rate). So, the analysis of this paper aims at capturing the main features of the euro area money market in a simple and parsimonious manner, closest in spirit to the recent study by Taylor (2001) for the market for federal funds in the United States.

As our objective is to model the regular provision of liquidity by the $\mathrm{ECB}$, the frequency of the model is weekly. ${ }^{5}$ At this frequency, the supply

\footnotetext{
${ }^{4}$ Moschitz (2002) and Würtz (2003) reach a similar conclusion working on euro area daily data. Angelini (2002), also studying daily data, however, finds evidence of a relatively small but significant liquidity effect early in the maintenance period.

${ }^{5}$ The ECB's main refinancing operations (MROs) are carried out at a weekly frequency. Normally, the MRO is announced on a Monday, the allotment is decided and announced on Tuesday morning, and the transactions are settled on Wednesday. There can be occasional deviations from this due to national holidays. For a detailed account of the operational framework and liquidity management in the euro area, see ECB (2002b); for a thorough analysis of the functioning of the interbank money
} 
of liquidity is mainly determined by the central bank, while autonomous factors play a more important role on a day-to-day basis. The (excess) demand for liquidity is determined by the actions of the banking system. Of course, the overnight rate in the euro area is determined by the interaction of demand and supply factors.

\subsection{The excess demand for liquidity and the overnight rate}

This section contains a simple model of excess demand for liquidity and the interbank overnight rate in the euro area, the foundations of which are mainly built on the related literature for the interbank market for the federal funds in the United States. ${ }^{6}$ In fact, although the operational framework in the euro area is different from that of the Federal Reserve and more similar to the "corridor" system in place for example in New Zealand and Canada, the key elements of commercial banks' demand for reserves identified in the US literature appear to be relevant also in the euro area.

A standard approach to modelling banks' demand for reserves is to consider a representative bank which has to satisfy a reserve requirement constraint defined over a multi-period maintenance period, and aiming at minimizing its total borrowing costs during the period. In this context, a conclusion is that, in the absence of frictions, the martingale property should hold, namely:

$$
r_{d}-E_{d} r_{d+1}=0
$$

where $r_{d}$ is the overnight rate on day $d$, and $E_{d}$ is the expectation conditional on the information available on day $d$. If there are no frictions in the market, any deviation from (1) would imply the possibility of an inter-temporal arbitrage. This, however, is ruled out by the assumption of rational expectations by market participants.

In realistic settings, however, in addition to changes in future expected overnight rates the current overnight rate might also be affected by current liquidity conditions prevailing, indicating the presence of a liquidity effect (Hamilton, 1996). A simple way to express this is to augment equation (1) by a term capturing the "liquidity situation" on day $d, L_{d}$ :

$$
r_{d}-E_{d} r_{d+1}=-\varphi L_{d}
$$

If $\varphi>0$, a shortage/overhang of reserves on day $d$ leads to an in-

market in the euro area from a microstructure perspective, see Hartmann, Manna and Manzanares (2001).

${ }^{6}$ It should be stressed from the onset that the focus of the present analysis is on the weekly level of the overnight rate, and not on its volatility. 
crease/decrease in the overnight rate on the same day, for a given expected level of the overnight rate prevailing in the remainder of the maintenance period (Taylor, 2001). For the market for federal funds in the United States, there is some evidence that a liquidity effect exists (i.e., $\varphi>0$ ) at a daily frequency (Hamilton, 1997). ${ }^{7}$ This might be due to a number of factors, including limits to credit lines, transaction costs, weekend accounting conventions (Hamilton, 1996), and reluctance to borrow from the discount window (Clouse and Dow, 1999). Some of these factors might also be relevant in the euro area (Bindseil and Seitz, 2001).

In this paper, we are interested in the excess demand function prevailing at the frequency which is relevant for the ECB's MROs, namely weekly. More precisely, we consider a frequency $t$ defined as the average of the variables between day $d$ and day $d+j$, where $d$ is the day of the MRO allotment (usually Tuesday every week) and $d+j$ is either the day before the following MRO (i.e. the announcement day) or the end of the maintenance period, whatever comes first. So, we set out to estimate the following equation:

$$
\frac{1}{j} \sum_{h=d}^{d+j}\left(r_{h}-E_{h} r_{h+1}\right)=-\frac{1}{j} \sum_{h=d}^{d+j} \varphi L_{h}
$$

We are interested in modelling the excess demand function as an average between day $d$ and time $d+j$ because this is the constraint which is relevant from the perspective of liquidity management in the euro area.

For simplicity of notation, let us define:

$$
\begin{aligned}
r_{t} & =\frac{1}{j} \sum_{h=d}^{d+j} r_{h} \\
E_{t} r_{t+1} & =\frac{1}{j} \sum_{h=d}^{d+j} E_{h} r_{h+1} \\
L_{t} & =\frac{1}{j} \sum_{h=d}^{d+j} L_{h}
\end{aligned}
$$

Accordingly, equation (2) may be rewritten at a weekly frequency as:

$$
r_{t}-E_{t} r_{t+1}=-\varphi L_{t}
$$

\footnotetext{
${ }^{7}$ However, Thornton (2001a) has recently claimed that Hamilton's results are not robust across different sample periods and are heavily influenced by outliers. See also Thornton (2001b).
} 
Further, let us define $s_{t}=r_{t}-m_{t}$, where $m_{t}$ is the main refinancing rate prevailing in week $t$, and $E_{t} \Delta_{t, t+1} s=E_{t} r_{t+1}-m_{t}$, i.e. the spread between future expected rates and the current level of the main refinancing rate. $^{8}$ So, equation (7) may be written as:

$$
s_{t}=E_{t} \Delta_{t, t+1} s-\varphi L_{t}
$$

Therefore, the EONIA spread $s_{t}$ is assumed to depend on two factors, the expectation of the spread prevailing in the future, computed against the current level of the main refinancing rate, $E_{t} \Delta_{t, t+1} s$, and current liquidity conditions, $L_{t}$. The term $E_{t} \Delta_{t, t+1} s$ may reflect either an expected change in the main refinancing rate during the maintenance period following a monetary policy decision, or the market's expectation of the ECB's liquidity policy later in the maintenance period. Essentially, our approach for the demand side of the model is to estimate equation (8) to test whether the parameter $\varphi$ is statistically different from zero.

One issue which is very relevant in this context and thoroughly debated in the US literature (see for example Thornton, 2001a) is the simultaneity problem. On a daily basis - the frequency normally used in the literature on the federal funds market - it is very difficult to distinguish between demand and supply factors when looking at the relationship between liquidity and interest rates. This has led researchers (for example Hamilton, 1997) to use instrumental variable methods or other econometric techniques to address the simultaneity problem.

We argue, however, that simultaneity should not be an issue for the weekly data that we use in the empirical analysis in this paper due to the sequencing of events and the time aggregation that we choose. To provide a simple visual description, the sequencing of events is illustrated in Figure 1.

After the MRO allotment which normally takes place on Tuesday each week, and apart from the net recourse to the standing facilities (normally significant only on the very last day of the maintenance period) and from underbidding episodes ${ }^{9}$, the liquidity situation is exogenous for the market and more importantly, for the central bank. In other words, in the days following a MRO and until the subsequent MRO, the supply of liquidity is determined by the past MRO allotment and

\footnotetext{
${ }^{8}$ Until April 1999, the main refinancing rate was not at the middle of the corridor, while it has always been at the middle of the corridor since then. As we do not use data prior to April 1999, we leave this complication aside in the paper and we refer only to the case of a symmetric corridor.

${ }^{9}$ When underbidding occurs at the MROs, banks bid less than the central bank's "neutral" MRO amount. In this way, the amount of the allotment is actually decided by the banking system, rather than the central bank. Underbidding occurred four times in our sample period.
} 


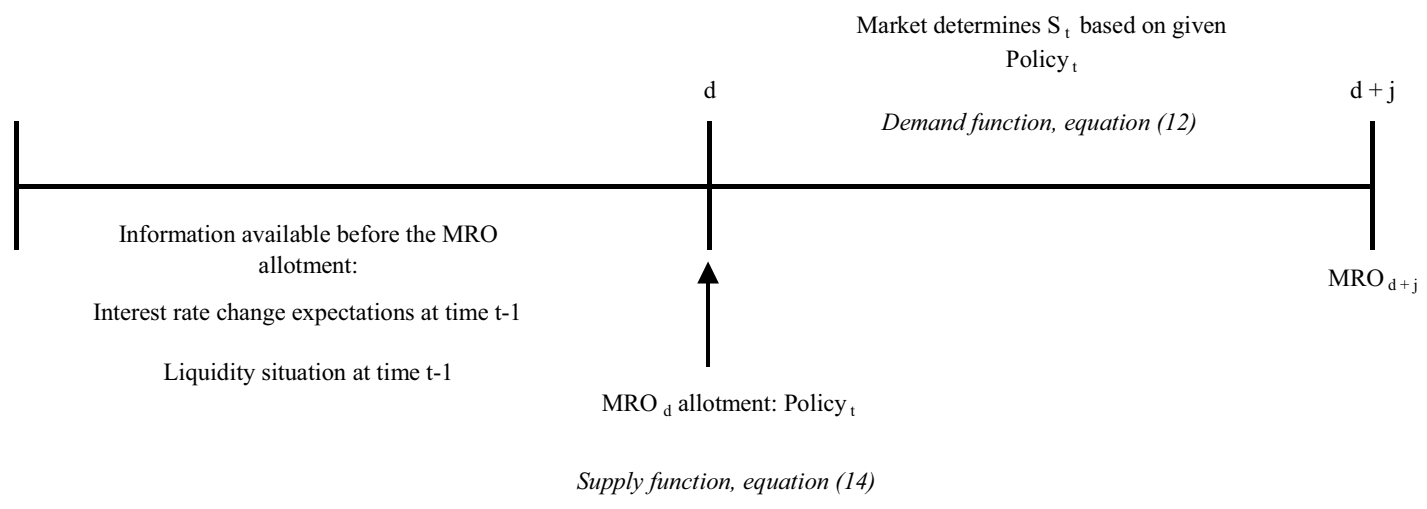

Figure 1: Simple visual description of the timing of the model.

by autonomous factor shocks, and is given for both market participants and the central bank and is not interest rate elastic (see Section 2.2 and 3.1 below for more details on the weekly averaging of variables). So, the overnight rate prevailing in the days after an MRO allotment and before the subsequent one - which is averaged over week $t$, i.e. between day $d$ and day $d+j$ - reflects only excess demand considerations, or in other words commercial banks' behaviour (see also Angelini, 2002). This is an important departure from the US operational setting, where the Fed intervenes in the market on a daily basis. Overall, therefore, equation (8) linking the EONIA spread to the liquidity situation can safely be interpreted as an excess demand relationship and can be estimated using OLS techniques.

In the empirical analysis, we have to make assumptions regarding the measures for the expected overnight rate prevailing in the future and for the liquidity situation, as both variables in equation (8) are not directly observable. For the expectational term $E_{t} \Delta_{t, t+1} s$, we use two different proxies based on short-term rates beyond the overnight maturity, namely the one-week forward rate prevailing in one-week time and the one-month forward rate prevailing in one-month time. It should be noted that both rates may be relatively imprecise estimates of interest rate expectations prevailing within the maintenance period, as they may be related to expectations on the level of the main refinancing rate in the subsequent maintenance period, especially in the latter case. Hence, we also estimate equation (8) including the lagged EONIA spread as a measure of interest rate expectations, based on the idea that, under the martingale hypothesis, the EONIA should contain all the information re- 
garding interest rate developments within the maintenance period. The objective is to check the robustness of the estimate of the coefficient $\varphi$ depending on the assumption for $E_{t} \Delta_{t, t+1} s$.

As regards the measure for the liquidity situation, $L_{t}$, we need to distinguish between the last week of the maintenance period (i.e., after the last MRO of the period) and the remaining weeks. ${ }^{10}$ In fact, in the euro area operational framework banks have to fulfil a reserve requirement defined in terms of an average over the maintenance period. So, in the last week the liquidity situation is certainly relevant from the standpoint of fulfilling the reserve requirement on average on the last day. For example, a positive shock to liquidity in the last week is bound to increase the likelihood for the banking system of having a net recourse to the deposit facility. By contrast, in the other weeks of the maintenance period the liquidity situation may be relevant only to the extent that, due to trading frictions, reserve holdings are not fully substitutable inter-temporally (Taylor, 2001; Bindseil and Seitz, 2001), or if market participants expect the central bank not to fully correct the existing liquidity imbalances in one of its subsequent MROs within the maintenance period.

Against this background, we estimate equation (8) distinguishing between the last week of the maintenance period (after the last MRO of the period) and the other weeks, as follows:

$$
s_{t}=E_{t} \Delta_{t, t+1} s-\varphi_{1} D E N D_{t} L_{t}-\varphi_{2}\left(1-D E N D_{t}\right) L_{t},
$$

where $D E N D_{t}$ is a dummy variable which takes value 1 if $t$ is the last week of the maintenance period, and zero otherwise. On the basis of the considerations above, it is reasonable to expect $\varphi_{1}$ to be strongly significant in the last week, while the significance of $\varphi_{2}$ is uncertain and depends on the structural features of the euro area money market and operational setting, in particular whether trading frictions make liquidity holdings imperfectly substitutable within the maintenance period. ${ }^{11}$

Overall, equation (9) is the basis of our empirical analysis for the demand side of the model. The model signals that the central bank can theoretically affect the overnight rate via two channels, namely expectations of future changes in the interest rate (through "open mouth"

\footnotetext{
${ }^{10}$ See Section 2.2 for a more precise definition of the measures used for the "liquidity situation" in the euro area.

${ }^{11}$ In this setting, a possible complication (and a source of possible non-linearity in the model) is the fact that the EONIA spread is constrained within the upper and lower bound of the corridor between the standing facilities. However, the overnight rate usually reaches one of the boundaries of the corridor only in the last hours of a maintenance period, if at all. On weekly averages, the possible impact of this non-linearity should be relatively small.
} 
operations) and the current liquidity situation (through open market operations). However, the distinction between open market and open mouth operations is less clear-cut if liquidity policy early in the maintenance period can provide credible signals about future monetary policy decisions within the maintenance period or about liquidity policy in the last MRO of the maintenance period, i.e. if liquidity policy is inertial within the maintenance period (see Woodford, 1999, on the role of policy inertia in steering market expectations about future policy actions).

\subsection{The supply of liquidity in the MROs}

\subsubsection{The regular supply of liquidity and the "liquidity situ- ation" in the euro area}

On any day $d$, the total supply of reserves by the ECB covers the elements which make up total demand (described thoroughly in ECB, 2002b):

$$
A F_{d}+\overline{R R}+E R_{d}=M R O_{d}+L T R O_{d}+F T O_{d}+N M L_{d}
$$

The components of the demand for reserves stem from the so-called autonomous factors, $A F_{d}$, of which banknotes in circulation and government deposits are the most important in terms of size and volatility, the imposed reserve requirement, $\overline{R R}$, which is assumed exogenous and constant over the reserve maintenance period, and finally, some demand for reserves in excess of the requirement, $E R_{d}{ }^{12}$ Banks' current account holdings with their respective national central banks is the sum of $\overline{R R}$ and $E R_{d}$. The bulk of central bank reserves are supplied in the MROs, $M R O_{d}$, which is the sum of the two outstanding (overlapping) operations, while the longer term refinancing operations, $L T R O_{d}$, are less important in size and void of any monetary policy signal. At banks' own discretion, funds can be obtained or deposited at the end of a trading session through the marginal lending and the deposit facility at penalty rates. $N M L_{d}$ is the net marginal lending by the banking system. Finetuning operations, $F T O_{d}$, may be launched by the ECB in exceptional circumstances.

Following closely ECB (2001) and ECB (2002b), the MRO allotment can be expressed in terms of a central bank target for excess reserves, and a MRO allotment ensuring "neutral" liquidity conditions in the market for reserves would thus seek to meet the "normal" level of excess reserves expected by the central bank: ${ }^{13}$

\footnotetext{
${ }^{12}$ Bindseil and Setz (2001) comprises a description of the individual liquidity components.

${ }^{13}$ The Federal Reserve tracks a similar expression of expected excess reserves in the US money market when making its daily decisions on supply of reserves.
} 
$E_{d}\left(\overline{E R}^{N O R M}\right)=M R O_{d}^{\text {Neutral }}+L T R O_{d}-E_{d}\left(\overline{A F}_{d, d+j}\right)-\overline{R R}$

$E_{d}\left(\overline{E R}^{N O R M}\right)$ is an estimate of the "normal" average daily level of excess reserves over a maintenance period, which typically was around EUR 0.7 billion in the sample period. Owing to the high level of required reserves in the euro area, banks have no fundamental reasons for holding excess reserves such as the liquidity services that they provide at the margin. So, the level of excess reserves is due almost entirely to technical reasons and is normally stable and predictable. ${ }^{14} \overline{A F}_{d, d+j}$ is the daily average of the autonomous factors from day $d$ until the following MRO allotment or the end of the maintenance period, whichever is first. Thus, $j$ is the number of days from a MRO on day $d$ in the maintenance period until the next MRO or the end of the maintenance period. In the last MRO allotment of a maintenance period, only the days remaining until the end of the prevailing maintenance period are taken into account (ECB, 2002b).

The "neutral" (or "benchmark") MRO allotment is such that the probability of having a net recourse to one of the two standing facilities at the end of the maintenance period is the same, i.e. $\frac{1}{2}$. Therefore, under the neutral allotment the expected overnight rate on the last day of the maintenance period is the same as the then prevailing main refinancing rate (which is also at the mid point between the standing facilities). If there are no expectations of a change in the main refinancing rate, this implies that, under the martingale hypothesis, the benchmark allotment ensures that the current overnight rate is very close to the current main refinancing rate (which is also expected to prevail on the last day of the maintenance period). However, the situation is not the same if there are expectations of a change in the main refinancing rate before the end of the maintenance period. In this case, the neutral allotment does not ensure that the overnight rate is close to the current main refinancing rate, but rather to the main refinancing rate which is expected to prevail on the last day of the maintenance period.

Recalling the variables used in the previous section, we define the liquidity situation on day $d, L_{d}$, as the difference between $E_{d}\left(\overline{E R}_{d+j}\right)$ and $E_{d}\left(\overline{E R}^{N O R M}\right)$, where $\overline{E R}_{d+j}$ is the daily average of the excess reserves accumulated from the first day of the reserve maintenance period until day $d+j$. A liquidity situation may be non-neutral due to deliberate policy actions or to shocks to autonomous factors. First, "nonneutral" liquidity policy actions can be taken by the ECB by supplying

\footnotetext{
${ }^{14}$ The exogenous nature of excess reserves in the euro area is discussed in detail in Bindseil et al. (2003).
} 
$E_{d}\left(\overline{E R}_{d+j}\right) \neq E_{d}\left(\overline{E R}^{N O R M}\right)$, i.e. by deviating from supplying the expected "normal" level of excess reserves. We call these policy actions Policy . In particular, when Policy ${ }_{d}$ is positive, the liquidity conditions are targeted to be "loose" (there is an excess of reserves in the market),

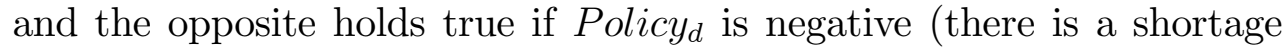
of reserves in the market). A non-neutral policy in the last week, if not counterbalanced by shocks in the autonomous factors, implies a non-zero net recourse to the standing facilities on the last day of the maintenance period, $N M L_{T}$, thereby pushing the EONIA rate towards the rate on one of the standing facilities. Second, shocks to the autonomous factors may entail deviations of the liquidity situation from the neutral level between two consecutive MROs, irrespective of the liquidity policy followed by the central bank. At the weekly MRO frequency, the liquidity situation $L_{t}$, i.e. the weekly average of $E_{d}\left(\overline{E R}_{d+j}\right)$ less $E_{d}\left(\overline{E R}^{N O R M}\right)$, may thus be decomposed into:

$$
L_{t}=\text { Policy }_{t}+\varepsilon_{t}^{A F},
$$

where the subscript $t$ indicates the weekly aggregation (average) between $d$ and $d+j$, where $d$ is the day of the MRO allotment, and $\varepsilon_{t}^{A F}$ is the average shock to the autonomous factors forecast (i.e., $\varepsilon_{t}^{A F}=\overline{A F_{t}}-$ $\left.E_{d} \overline{A F}_{t}\right)$. It should be emphasized that the recourse to the standing facilities is not included in $L$, which is a concept close to the "nonborrowed" reserves in the US. ${ }^{15}$

\subsubsection{A liquidity reaction function for the central bank}

Which considerations drive the liquidity allotment at the MROs? Some elements affecting the supply of liquidity can be extracted from the ECB's "General Documentation" (ECB, 2002a):

Open market operations play an important role in the monetary policy of the Eurosystem for the purposes of steering interest rates, managing the liquidity situation in the market and signalling the stance of monetary policy (ECB, 2002a, p. 4) [emphasis ours]

In the following, we test to what extent this implies a preference for at least the following two elements: (i) a smooth path of provision of liquidity to banks and (ii) interest rate smoothing within the maintenance

\footnotetext{
${ }^{15}$ Banks typically take recourse to standing facilities to offset liquidity shocks, in particular towards the end of the maintenance period. Hence, if the use of standing facilities were included in the liquidity condition measure, $L$, most liquidity shocks would not be observed.
} 
period, minimizing deviations of the very short-term interest rates from the main refinancing rate. For our purpose, these two considerations could be translated into a simple loss function of the following form, where the EONIA spread is used as a proxy for the short-term interest rates relevant for the ECB's liquidity policy:

$$
\text { Loss }_{t}=\gamma \text { Policy } y_{t}^{2}+(1-\gamma) s_{t}^{2},
$$

where $\gamma$ captures the relative importance attributed to liquidity and interest rate smoothing. Bindseil (2002) and Välimaki (2002) present loss functions based on similar considerations. ${ }^{16}$ In particular, (13) posits a preference for a smooth provision of liquidity implying that deviating from the neutral allotment Policy $=0$ is costly for the central bank. Arguments for the inclusion of this term may be, for instance, that the central bank finds it desirable to create predictable liquidity conditions for the market, that some market segments may be favoured unduly by volatile allotments, and that banks themselves may have preferences for a relatively smooth pattern of reserve fulfilment to reduce the risk of having to catch-up or dispose of funds significantly on the last days of the maintenance period. Bindseil (2002) mentions that large fluctuations in total bank reserves may be welfare-reducing as in particular low levels of reserves reduce the buffer against various aggregate and individual shocks. Concerning interest rates, (13) suggests that the central bank may seek to reduce deviations of the overnight rate (and other short-term interest rates) from the main refinancing rate in order to support, and give credibility to, the signalling of the monetary policy stance via the main refinancing rate and the corridor between the rates on the standing facilities.

It should be noted at this stage that the objectives of liquidity and interest rate smoothing are normally mutually consistent, because a neutral allotment - especially in the last MRO of the maintenance period - normally ensures that the current overnight rate is very close to the main refinancing rate. A trade-off between liquidity and interest rate smoothing, however, may arise if there are expectations of a change in the main refinancing rate within the maintenance period or expectations of a liquidity imbalance at the end of the period, whereby the EONIA spread $s_{t}$ may be affected by a non-zero expectation term $E_{t} \Delta_{t, t+1} s$. In this case, if the central bank wanted to signal that the interest rate expectations might not be warrented, it could try to lean against expectations by conducting an active liquidity policy, i.e. departing from

\footnotetext{
${ }^{16}$ Ayuso and Repullo (2000) propose an asymmetric loss function for liquidity management in the euro area penalising downside deviations of the EONIA from the middle of the corridor more heavily than upward deviations.
} 
the neutral allotment Policy $=0 .{ }^{17}$ In turn, an active liquidity policy implies a departure from a smooth provision of liquidity, which may be costly for the central bank, at least according to equation (13).

Against this background, what is the "liquidity reaction function" of the ECB? Some further elements have been provided by the ECB itself:

A so-called benchmark allotment can be calculated on the basis of the liquidity needs. This benchmark constitutes a baseline for the ECB when making its actual allotment decisions. However, the ECB may sometimes also have to consider other elements, such as counterparties' bidding behaviour in the MROs and the divergence of the short term money market interest rates from the $M R O$ rate, as well as some exceptional factors creating extraordinarily high uncertainty about liquidity forecasts. (ECB, 2002b, p. 6). [emphasis ours]

So, the central bank aims at ensuring a balanced liquidity situation, where liquidity is allotted so as to satisfy banks' liquidity needs $\left(\right.$ Policy $\left._{t}=0\right)$, but it may also deviate from this "benchmark" allotment as a response to fluctuations in the EONIA spread (or the spread between other short-term interest rates and the main refinancing rate) as well as due to exceptional circumstances.

We test a reaction function very close to those proposed by Feinman (1993) and in particular Taylor (2001) in the US, to examine whether this is an appropriate starting point for characterizing liquidity policy also in the euro area. The policy rule is the following:

$$
\text { Policy }_{t}=\alpha+\beta E_{t-1} \Delta_{t, t+1} s+\theta \text { Policy }_{t-1}+\omega D_{t}
$$

A linear relationship between the Policy variable and the interest rate expectation term $E_{t-1} \Delta_{t, t+1} s$ can be derived theoretically directly from the minimization of the loss function in (13) under a partial adjustment mechanism, as shown in Annex I. ${ }^{18}$ However, the empirical reaction function in (14) is slightly broader than the theoretical one, as

\footnotetext{
${ }^{17}$ By contrast, in cases where the central bank itself signalled that a monetary policy change may be forthcoming, it may be rational for it not to seek to reduce the spread of market rates from the prevailing policy rate.

${ }^{18}$ In Annex I the liquidity reaction function which minimizes the central bank loss function in (13) is derived under discretion, i.e. taking market expectations as given, hence under the assumption that the central bank cannot credibly commit to follow a liquidity allotment policy rule. Solving the problem under commitment would raise complex issues of time inconsistency which go beyond the scope of the current analysis.
} 
it also includes a constant term and a vector of dummy variables to cater for special episodes.

Assuming that the central bank has a preference for neutral allotments, we would expect the constant term $\alpha$ to be insignificant, i.e. that the benchmark allotment would prevail on average (Policy $=0$ on average). If the central bank is seeking to smooth interest rates around the main refinancing rate, as the loss function in (13) also suggests, liquidity policy reacts to existing interest rate change expectations, $E_{t-1} \Delta_{t, t+1} s$. In fact, the EONIA rate can depart from the main refinancing rate due to either interest rate change expectations or liquidity conditions, as emphasized by equation (8). If the coefficient $\beta$ is positive, the central bank leans against interest rate deviations from the main refinancing rate prior to the MRO allotment at time $t$. There is a direct relationship between the size of the response to existing interest rate expectations (coefficient $\beta$ ) and central bank preferences. In particular, as discussed in Annex I, if $\gamma=1$ (the central bank cares only about liquidity smoothing), we have $\beta=0$. So, the central bank does not react to interest rate expectations at all. Conversely, if $\gamma=0$ (the central bank cares only about interest rate smoothing), and assuming complete adjustment $(\theta=0)$, we should have Policy $_{t}=\frac{1}{\varphi} E_{t-1} \Delta_{t, t+1} s$, which in turn implies $E_{t-1} s_{t}=0$ at all $t$. In this case, the central bank uses liquidity policy exclusively in order to keep the overnight rate exactly at the main refinancing rate.

It is also to be noted that that in our setting liquidity policy reacts to interest rate expectations with a lag, which ensures that this identifies a supply function and is also appropriate given that $E_{t} \Delta_{t, t+1} s$, a weekly average, is not in the information set of the central bank at the time of the allotment (the starting point of the weekly period), while $E_{t-1} \Delta_{t, t+1} s$ is (the method for addressing simultaneity was discussed in greater detail in section 2.1). Taylor (2001) makes a similar assumption for the Federal Reserve's Open Market Desk reaction function. ${ }^{19}$ In the empirical analysis, we use four main proxies for prevailing interest rate change expectations $E_{t-1} \Delta_{t, t+1} s$, namely (i) the EONIA, (ii) the two-week EONIA swap rate, (iii) the one-week forward rate in one week, and (iv) the one-month forward rate in one month - all of them computed as a spread on the current main refinancing rate. The considerations outlined for the demand side of the model regarding the proxies for interest rate

\footnotetext{
${ }^{19}$ Orphanides (2001) criticizes Taylor's assumption that the lagged federal funds rate enters in the liquidity reaction function, based on the idea that the Federal Reserve should react to the future expected federal funds rate, rather than the past one. Our reaction function is forward-looking in nature, however, as will be seen in the next section, the results are similar whether using forward rates or the EONIA as a proxy for the interest rate expectations.
} 
expectations apply also to the supply side of the model. However, for the supply side of the model only we also add the two-week rate because this is the same maturity of the MROs and may therefore be relevant from a liquidity policy perspective.

\section{The empirical evidence}

\subsection{The data}

Our sample of weekly observations is derived from daily data from 4 January 1999 to 23 November 2002, resulting in 202 weekly observations, which is the number of MROs carried out in that period. All data are drawn from ECB sources. ${ }^{20}$ However, in the analysis we leave out the first months of 1999 which marked the beginning of Stage Three of EMU and may be characterized as a learning period, both for the banks and the ECB, in the new environment and operational framework. Estimates based on these first months might provide misleading results, as time series break tests also suggest. Overall, we decide to start our sample period in August 1999, resulting in 172 weekly observations.

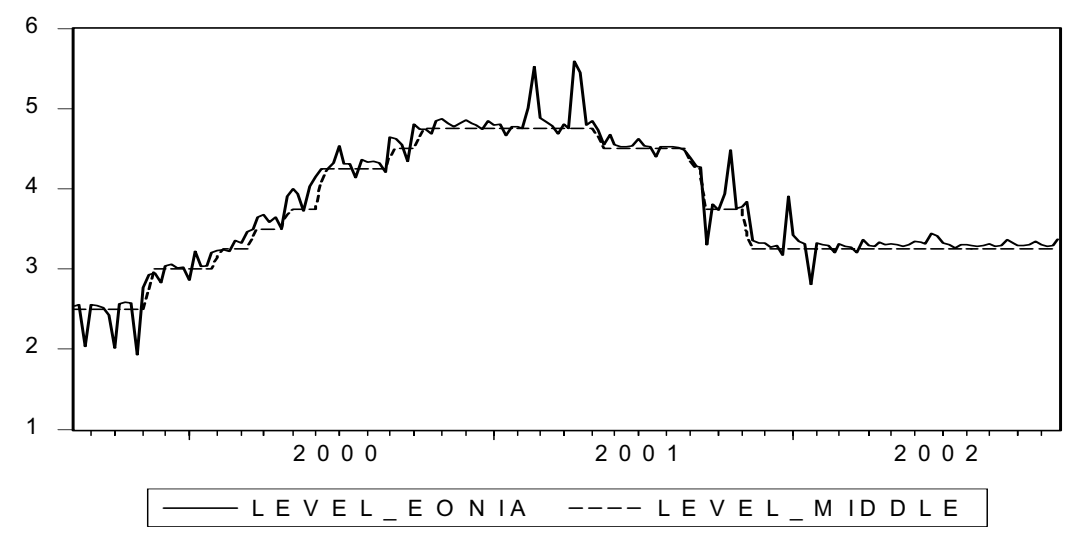

Figure 2: EONIA and the middle of the corridor

A key variable in our analysis and for liquidity policy in the euro area is $s_{t}$, i.e. the EONIA spread. Weekly averages of the EONIA rate and the main refinancing rate are reported in Figure 2 while the EONIA

\footnotetext{
${ }^{20}$ The ECB publishes its liquidity data daily on the Reuters ECB40 page together with weekly forecasts of liquidity needs. Time series of these variables are available on the ECB website www.ecb.int. By using this data and applying the methodology outlined in ECB (2001) and (2002b) the liquidity data used in this study can be roughly replicated. The interest rate measures are available through practically all financial data providers.
} 
spread is reported in Figure $3 .^{21}$ Generally speaking, the EONIA rate has been very close to the main refinancing rate and deviations have normally been small and temporary, although there are some infrequent spikes both up and down, mainly at the end of maintenance periods.

Some key statistics on the EONIA spread are reported in Figure 4. The average spread was 7 basis points, with a standard deviation of 17 basis points. The spread is highly non-Normal, indicating the importance of some large outliers in the distribution, and is also skewed (the median spread is slightly lower, at 5 basis points). Moreover, standard unit root tests overwhelmingly reject the hypothesis that the EONIA spread is non-stationary.

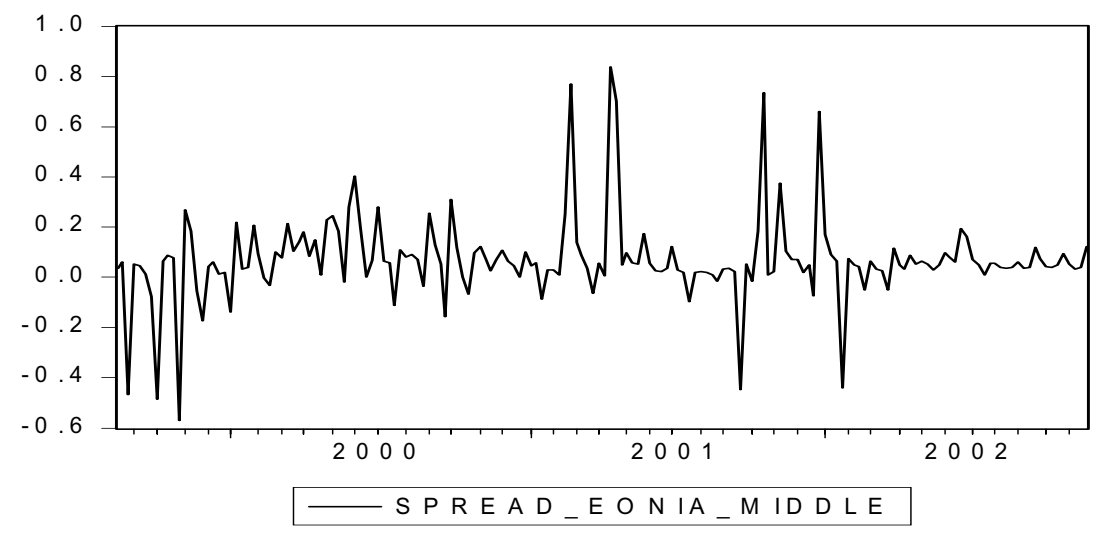

Figure 3: Spread between EONIA and the middle of the corridor

As a measure of interest rate expectations for the demand side of the model, $E_{t} \Delta_{t, t+1} s$, we consider the lagged EONIA spread as well as the spread between two short-term rates and the main refinancing rate, in particular (i) the one-week forward rate prevailing in one-week time and (ii) the one-month forward rate prevailing in one-month time. These forward rates are computed from EONIA swap interest rates. As noted previously, for the supply equation we also test the use of the two-week EONIA swap rate.

Coming to the liquidity variables, the dependent variable of the supply equation, Policy, measures the difference between the target daily average reserve surplus decided by the ECB at each MRO for the next allotment (determined when the allotment decision is made) and a benchmark value, which is an estimate of the "normal" daily average reserve

\footnotetext{
${ }^{21}$ Please note that we assume that changes to the main refinancing rate take effect the day after their announcement (the day that changes to the standing facilities are implemented) instead of after the following main refinancing operation.
} 


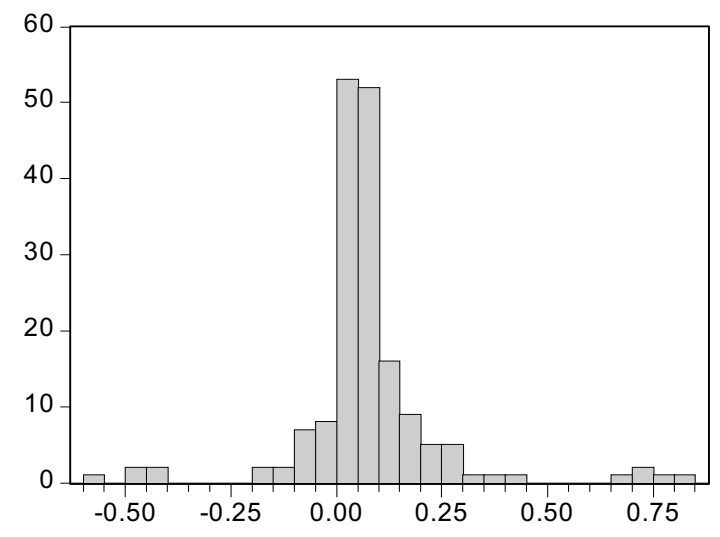

\begin{tabular}{|lc|}
\hline Series: SPREAD_EONIA_MIDDLE \\
Sample 8/15/1999 11/24/2002 \\
Observations 172 \\
Mean & 0.070261 \\
Median & 0.052429 \\
Maximum & 0.838750 \\
Minimum & -0.570000 \\
Std. Dev. & 0.171993 \\
Skewness & 0.876470 \\
Kurtosis & 10.75865 \\
& \\
Jarque-Bera & 453.4309 \\
Probability & 0.000000 \\
\hline
\end{tabular}

Figure 4: Key statistics on the spread between EONIA and the middle of the corridor

surplus demanded by the banking system over a maintenance period (EUR 0.7 billion in the sample period). This variable is thus already of a weekly frequency, occurring on the allotment day of a given MRO. When liquidity policy is neutral, the target daily average reserve surplus minus the "normal" demand for excess reserves, Policy $y_{t}$ would be zero. Otherwise, a negative value would signal a tight allotment and a positive value a loose one. In addition, we also consider the average forecast error on the autonomous factors, $\varepsilon_{t}^{A F}$, obtained as a weekly average of daily forecast errors compared with the internal ECB forecasts. ${ }^{22}$ A positive value of $\varepsilon_{t}^{A F}$ implies looser than neutral liquidity conditions. Figure 5 reports the Policy variable and the forecast errors for the autonomous factors, which are the two components of the overall liquidity situation variable $L_{t}=$ Policy $_{t}+\varepsilon_{t}^{A F}$. It can be seen from the chart that there are a few outliers in the Policy series, but fluctuations are otherwise quite contained.

The key statistics for these liquidity situation variables, reported in Figures 6 and 7, show that conditions have been balanced on average, indicating that liquidity policy has been neutral over a long period of time.

The neutral character of liquidity policy is confirmed by looking at the net recourse to the marginal lending facility (where positive values indicate that the recourse to the marginal lending facility were larger

\footnotetext{
${ }^{22}$ Note that we assume that the forecast for the autonomous factors of the central bank and of the market is the same. While this is not necessarily always true, there is no reason to believe that market forecasts are biased.
} 


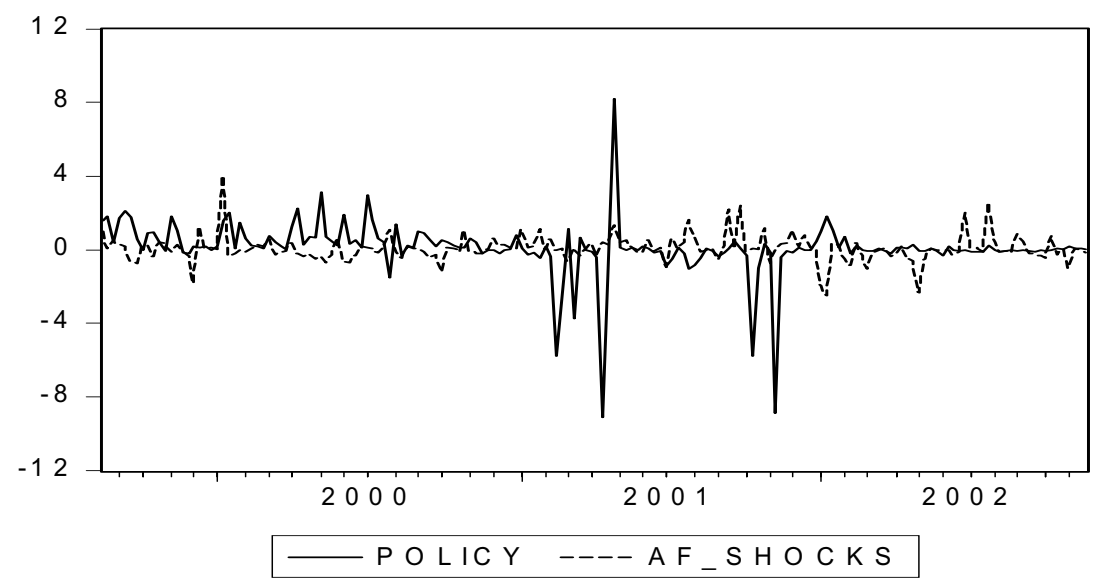

Figure 5: Demand and supply variables: the two components of the liquidity situation, Policy and autonomous factor shocks

than that to the deposit facility), which has also been very close to zero on average (see Figures 8 and 9 ).

Furthermore, in the analysis we also use a set of dummy variables to control for some special episodes which occurred during our sample period, as well as the dummy variable $D E N D_{t}$ which is used to differentiate the last week of the maintenance period from previous weeks for our main variables, as explained ealier in the paper. The dummy variables for special episodes are the following:

- Dummy for the underbidding episodes of 13 February, 10 April, 9 October and 6 November 2001.

- Dummy for the end of the month. It picks the MRO closest to the end of the month, generally the first or second MRO of the maintenance period, during 1999 and 2000 (it was found not significant for 2001 and 2002).

- Dummies assuming the value one on 6 March and 24 April 2001 where the allotments were anomalous due to the diverging size of the two outstanding MROs.

- Dummy that picks the allotments on 20 February, 18 April, and 16 October 2001 where the ECB only partially covered for the liquidity shortfall stemming from the underbidding in the preceeding MROs of 13 February, 10 April and 9 October 2001, respectively. 


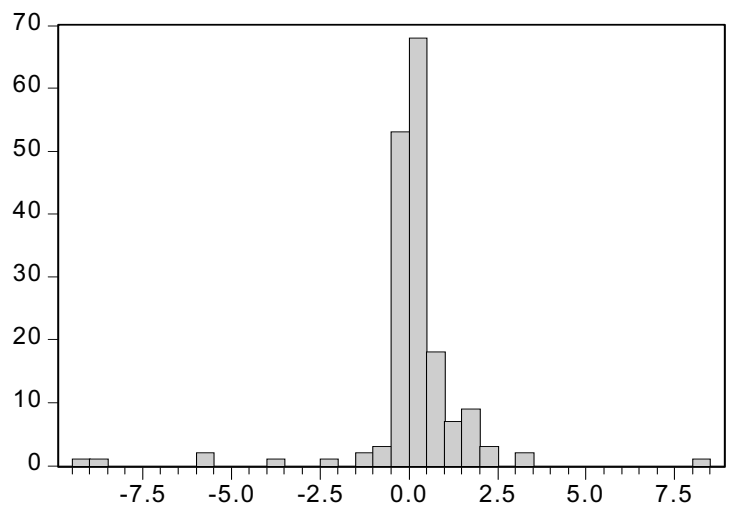

Figure 6: Key statistics on the Policy variable

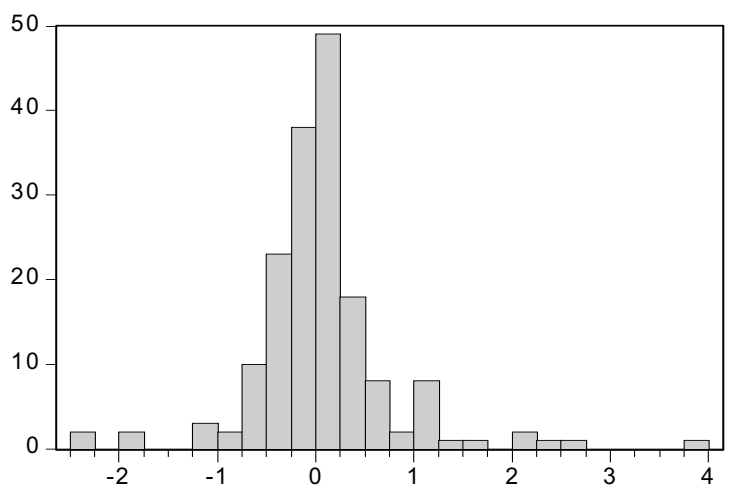

Figure 7: Key statistics on the autonomous factor shocks variable

- Dummies for fine-tuning operations picking the MRO allotments on 11 January 2000, 27 June 2000, and 8 and 15 January 2002 succeeding the weeks of fine-tuning (the fine-tuning the 18 September 2001 is accounted for below).

- Dummy that picks the allotment on 18 September 2001 following the terrorist attacks in the US.

- Dummy that assumes the value one in the MROs in the maintenance periods of third quarter 1999, in which the ECB generally allotted ample liquidity to counter overbidding.

- Dummy that picks the last observation of each year. 


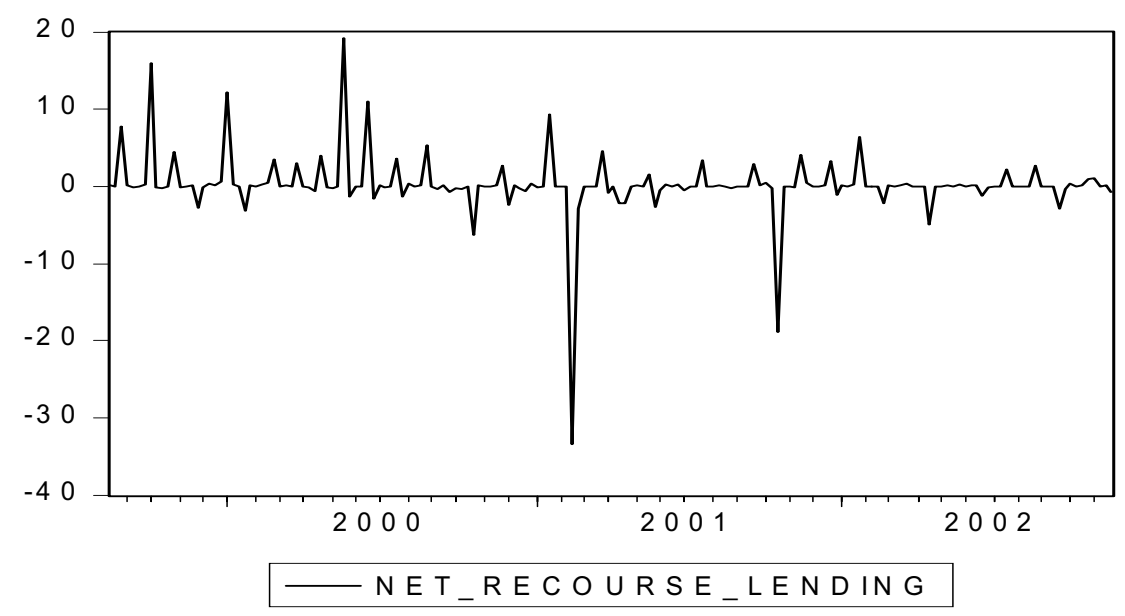

Figure 8: Net recourse to the marginal lending facility (Positive values indicate that the recourse to the marginal lending facility were larger than that to the deposit facility)

- Dummy taking a value of one for the allotment on 28 December 2001, the last tender of the year 2001, immediately prior to the cash changeover.

- Dummy that assumes the value one on 22 January 2002, the last MRO of the maintenance period ending on the 23 January 2002, which was affected by the cash changeover.

For the variables used in the empirical analysis, the weekly aggregation (i.e., from frequency $d$ to frequency $t$ ) is carried out as reported in detail in the Chart in Annex II. The liquidity variable $\varepsilon_{t}^{A F}$ is aggregated as the daily average between the settlement day of the MRO and the allotment day of the following $\mathrm{MRO}$, or the last day of the maintenance period (whatever comes first). Because interest rates may be affected by liquidity policy already on the allotment day, we aggregate all interest rate measures (in particular, $s_{t}$ and the proxies for $E_{t} \Delta_{t, t+1} s$ and $\left.E_{t-1} \Delta_{t, t+1} s\right)$ between the allotment day and the announcement day of the subsequent MRO.

The weekly observation which refers to the last week of the maintenance period aggregates over a variable number of days (around half a week on average). Because we have designed the demand and supply models as linear models and have derived the time aggregation explicitly, this should not affect our results to a significant extent. However, in the demand function this time aggregation is an issue if the effect of 


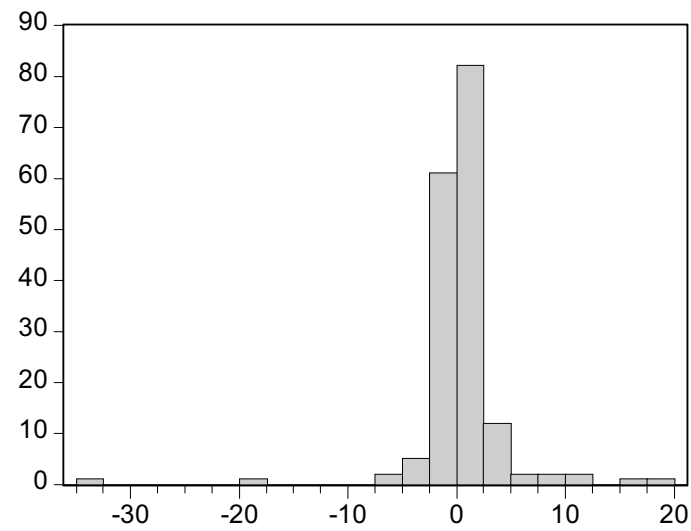

Series: NET RECOURSE LENDING

Sample 8/15/1999 11/24/2002

Observations 172

Mean $\quad 0.229250$

Median $\quad 0.017000$

Maximum $\quad 19.20300$

Minimum $\quad-33.39900$

Std. Dev. $\quad 4.097907$

Skewness $\quad-2.554243$

Kurtosis $\quad 34.45982$

Jarque-Bera $\quad 7280.020$

Probability $\quad 0.000000$

Figure 9: Key statistics on the net recourse to the marginal lending facility

the liquidity is larger on the very last day of the maintenance period, as some empirical evidence appears to suggest (Moschitz, 2002; Würtz, 2003). The weight of the last day is larger, the shorter the last week of the maintenance period. So, to the extent that this is the case our results should indicate the average effect of the liquidity situation onto the EONIA spread, i.e. for a hypothetical last week of 3.5 days. We also test whether the variable length of the last week has an impact on our results.

\subsection{Estimation and results}

\subsubsection{The excess demand for liquidity}

Table 1 in Annex II reports the results of estimating the demand equation in (9) using simple OLS making three different assumptions for the interest rate expectations terms, $E_{t} \Delta_{t, t+1} s$, as reported in the previous section. The estimates in the table treat the liquidity situation as due to Policy and to shocks to the autonomous factors, $\varepsilon_{t}^{A F}$, separately in order to distinguish between policy-induced liquidity imbalances and those resulting from stochastic shocks to liquidity. It is interesting to note, in particular, that the measure of interest rate expectations based on the lagged value of the EONIA spread $s_{t-1}$ (first column on the left in Table 1) gives satisfactory results, also in terms of diagnostic statistics (reported in the lower part of the table). There is no evidence of serial correlation and ARCH effects in the residuals. While the RESET test indicates that there is some sign of residual non-linearity in the model, 
this is not the case when estimating the same function based on $L_{t}$, i.e. without separating Policy and $\varepsilon_{t}^{A F}$ (see following Table 2), although the test is close to be significant also in this case. Furthermore, tests of the residuals against the explanatory variables shows no presence of non-linearities and thus supports the linear approximation. ${ }^{23}$ Whereas the Jarque-Bera test consistently signals the presence of non-Normality in the residuals, it has to be taken into account that it is normally difficult to obtain Normal residuals with high frequency data. Breakpoint Chow tests tend to suggest that all models in Table 1 are relatively stable. In particular, there is no sign that the switch to the variable rate tender system in June 2000 has changed the parameters of the demand function to any statistically significant extent. Overall, the model including $s_{t-1}$ as a measure of interest rate expectations can be considered as the "benchmark" model for the demand side of the model, due to its simplicity and satisfactory diagnostic statistics.

The main message arising from the results in the table is that the liquidity situation, as proxied by the Policy and $\varepsilon_{t}^{A F}$ variables, has had a strong and significant impact on the EONIA spread only after the last MRO of the maintenance period. The estimate of this liquidity effect is remarkably consistent across measures of interest rate expectation, ranging between -0.37 and -0.41 . Moreover, we do not find a statistically significant difference between the impact of liquidity shocks arising from Policy and from autonomous factors, $\varepsilon_{t}^{A F}$. When estimating the equation using the $L_{t}$ variable for total liquidity shocks (as done in Table 2 ), we find that the effect on the last week of the maintenance period is -0.37 , while for previous MROs it is a mere -0.02 , both of which are statistically significant. Overall, these results imply that a shortage from the "normal" average daily demand for excess reserves (around EUR 0.7 billion) of, say, EUR 1 billion in the last week of the maintenance period leads to an increase in the average EONIA spread by around 37 basis points. ${ }^{24}$ By contrast, liquidity effects are found to be marginal for

\footnotetext{
${ }^{23}$ We also try to include a non-linear term $L_{t}^{2}$ in the demand equation to cater for possible non-linearity effects (not shown for brevity), finding that such non-linearities are statistically significant but very small and do not improve the overall fit of the equation to a noticeable extent. So, we prefer to stick to the more tractable linear approximation.

${ }^{24}$ The magnitude of the estimated liquidity effect after the last MRO of the maintenance period is comparable to previous estimates. Studies using daily data have found an impact on the EONIA of roughly 4 basis points from a EUR 1 billion liquidity imbalance on the last day of the period (Bindseil and Seitz, 2001; Würtz, 2003). If the impact on the EONIA occurred entirely on the last day of the maintenance period, the average weekly impact of 37 basis points would translate into an impact of 4.3 basis points from a EUR 1 billion liquidity imbalance on the last day of the period (dividing by 30 days translates a EUR 1 billion daily average imbalance into
} 
shocks taking place before the last $\mathrm{MRO}$ of the maintenance period. The same EUR 1 billion liquidity imbalance would move the EONIA spread by only 2 basis points on average, based on our estimates.

In Table 2 in Annex II we report the results when estimating the benchmark equation using $L_{t}$ for all liquidity shocks, not distinguishing between Policy and $\varepsilon_{t}^{A F}$, as mentioned above. In parallel, we check whether a variable capturing the deviation in the number of days from the average number of days of the last week of the maintenance period matters in determining the slope of the demand curve in that week. As noted in Section 3.1, the argument would be that in a shorter/longer last week the weight of the very last day - where the bulk of the liquidity effect is presumably concentrated - would be bigger/smaller, and this might affect the slope of the demand function. However, we find this variable to have a very small and statistically insignificant impact (see Table 2, right column).

Further insight on the benchmark demand function may be gained by looking at the stability analysis, which is reported in Figure 11. Recursive residuals and the CUSUM test show no sign of instability in the benchmark demand function. At the same time, a few outliers are visible in the residuals chart shown in Figure 10, which are related to some specific circumstances which occurred during the sample period. In particular, these episodes refer to underbidding in 2001 and to two very special circumstances, namely the terrorist attacks on 11 September 2001 and the cash changeover related effects at the end of 2001 and in the maintenance period ending on 23 January 2002.

To check the robustness of the results of the benchmark demand function to these special episodes, in Table 3 in Annex II we report an estimate of the model including different sets of dummy variables. The inclusion of these dummy variables does not change the qualitative conclusion of the analysis, namely that liquidity imbalances matter for the EONIA spread to a significant extent only after the last MRO of the maintenance period. Moreover, we also separate positive and negative values of $L_{t}$ to check for the possible presence of asymmetric effects. In the first column on the left, we simply present the equation with the asymmetry, where we find evidence of a relatively stronger effect of positive values than of negative values of $L_{t}$. So, it seems that a "squeeze" in liquidity has a smaller effect on the EONIA than a loosening of conditions. This is an interesting result which appears to be difficult to

a EUR 1 billion imbalance on the last day and then assuming that the average last week of the maintenance periods was 3.5 days). However, this is only a crude measure of comparison. 


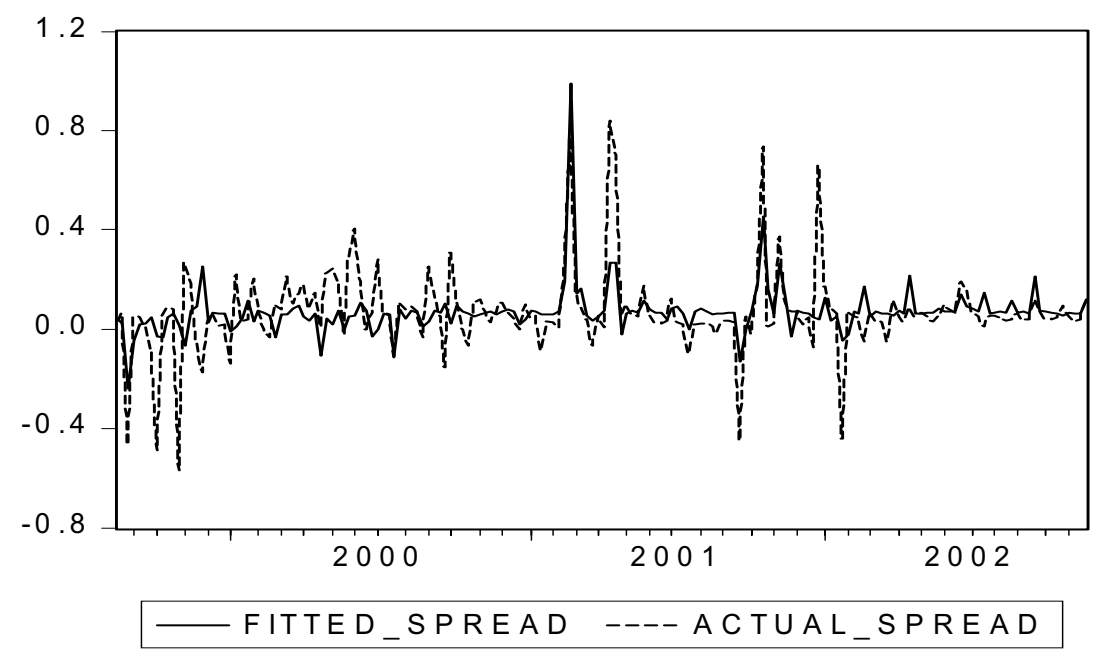

Figure 10: Actual and fitted values of the EONIA spread in the "benchmark "demand equation

justify based on purely rational considerations. ${ }^{25}$ However, this evidence of asymmetry should not be overemphasized because we have relatively few episodes of large negative values of $L_{t}$ in our sample period. This is also confirmed when controlling for the "no bail-out" allotments pursued by the ECB following in particular three underbidding episodes in the course of 2001, which have generally resulted in large negative values of $L_{t}$ (second column from the left). In this case, negative values of $L_{t}$ are not even significant in the estimate, indicating a sensitivity to a few observations due to small sample bias. In the subsequent columns, we also dummy out the effect of the terrorist attacks on 11 September 2001, the year-end effect in 2001 and the cash changeover, as well as the three "no bail-out" episodes separately, rather than together.

All in all, the results of the analysis of the demand function indicate that there is a consistent pattern in all estimates which points to a strong effect of liquidity after the last MRO of the maintenance period, with a coefficient of around -0.37. By contrast, the effect of the liquidity situation variables on the EONIA spread is marginal or non-existing before the last MRO of the maintenance period. This feature is likely to

\footnotetext{
${ }^{25}$ An explanation of the finding, which could be consistent with rationality, is that, as the interest rate decreases (following a positive liquidity shock), more banks may see little marginal benefit from managing their reserves actively and may simply use the deposit facility. This behaviour could be rational when transaction costs or other frictions are present.
} 


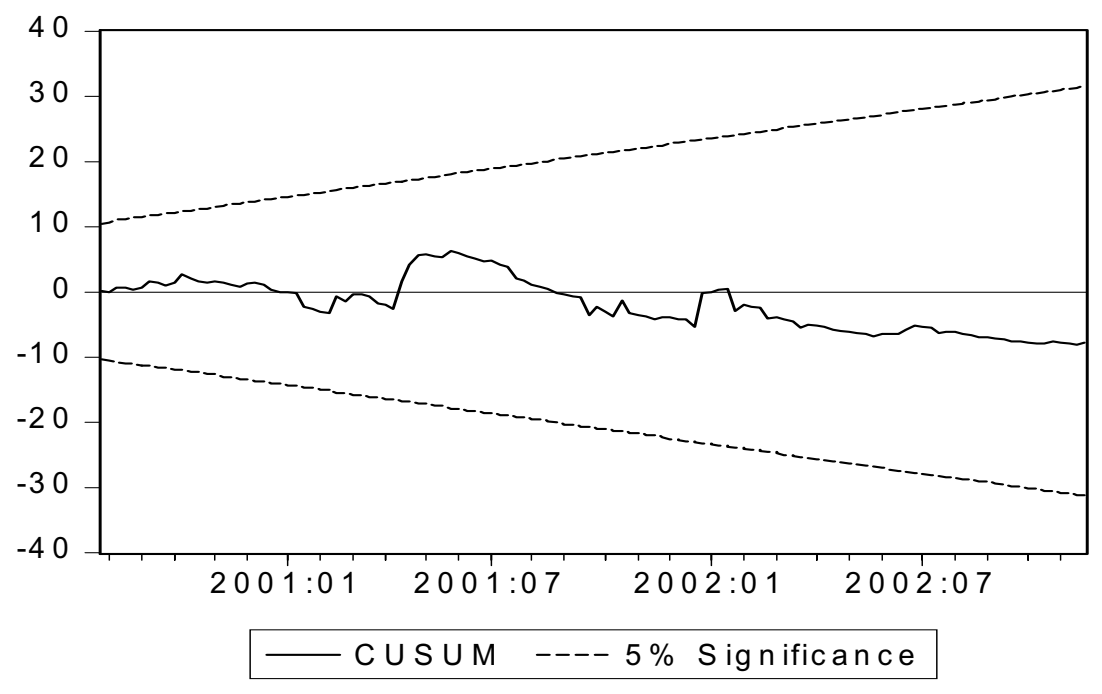

Figure 11: Recursive residuals and CUSUM tests of the "benchmark" demand equation

reflect both structural features of the euro area money market as well as the market's perception of the ECB's liquidity policy within the maintenance period. First, the level of the reserve requirement in the euro area and the possibility of averaging is likely to imply that the liquidity services provided by an additional unit of reserves has been practically zero before the end of the maintenance period (banks are "satiated" with reserves). So, a liquidity imbalance (for example a shortage of reserves) early in the maintenance period, at least of the relatively limited size observed so far, has had no effect on the price of liquidity, i.e. the overnight rate. The result also suggests that the reserve requirement with averaging provision has been successful in cushioning effects from liquidity imbalances until the very last days of the maintenance period. Second, market participants most likely expected the ECB to be approximately neutral in the last MRO of the maintenance period (see the next Section), namely to correct any early imbalance in liquidity later in the maintenance period. The consequence of this is that a liquidity imbalance early in the maintenance period was seen as having no bearing on the expected liquidity situation in the last week (more precisely, on the last day) of the maintenance period, which is what matters for the current overnight rate under the martingale hypothesis. This interpretation is supported especially by the observation that the liquidity effect is found to be very small before the last MRO of the maintenance period 
across all measures of interest rate expectations, irrespective of whether they span the current maintenance period (the lagged EONIA spread) or the following one (the one-month forward rate in one month).

Summing up, the demand for liquidity in the euro area can be represented by the following function at a weekly frequency (dropping insignificant terms for simplicity):

$$
s_{t}=0.06+0.14 s_{t-1}-0.37 L_{t} D E N D_{t}-0.02 L_{t}\left(1-D E N D_{t}\right),
$$

where 0.06 (six basis points) may be seen as a crude measure of the "natural spread" between the EONIA rate and the main refinancing rate. $^{26}$

\subsubsection{The supply of liquidity}

Turning to the supply of liquidity, several money market rates are used to proxy the expectation for the future EONIA spread, $E_{t-1} \Delta_{t, t+1} s$. Table 4 in Annex II reports the results of a simple OLS estimation of equation (14) for the three alternatives; the EONIA, the two-week EONIA swap rate, and the one-month forward rate in one month calculated from EONIA swap rates, all of them computed as a spread over the main refinancing rate, as already mentioned in previous sections.

Unanimously, the estimations confirm that $\beta$ is significant and positive and that the constant $\alpha$ is not significant. The coefficient to the lagged dependent variable, $\theta$, is significant and positive only in the specification using the EONIA, however, also in that case the coefficient is very small. In the specifications using other interest rate proxies the coefficient is insignificant. Hence, there appears to have been no systematic inertia in the liquidity policy of the ECB in the sample period.

We find that the one-month forward rate in one month dominated the one-week forward rate in one week, which is therefore not reported in Table 4. While the one-week forward rate may contain more information about expectations for rate changes within the maintenance period, it is also more prone to short-term noise. The one-month forward rate, although containing expectations for changes in the main refinancing rate and the interest rate corridor beyond the prevailing maintenance period, may nevertheless be a somewhat more reliable proxy for the expectations within the prevailing period. For the one-month forward rate, we also find that the observation on the announcement day carried higher explanatory power than the average of the rate over the previous week. For the two-week spot rate and the EONIA, the opposite holds true. For

\footnotetext{
${ }^{26}$ Würtz (2003) uses a highly parameterised daily model and finds a natural spread of around 2.5 basis points.
} 
the spot rates, the average of the past week entailed a stronger explanatory value, indicating that the weekly average may be a more reliable signal of market conditions than the single value on the announcement day. ${ }^{27}$

When ranking the estimations with the alternative interest rate proxies by the information criteria, the estimation based on the lagged EONIA spread dominates the alternatives, although the difference is small. The short-term forward rates contain important information on market expectations for the future path of the main refinancing rate. However, the overnight maturity may be at least as important for the ECB since, under the martingale hypothesis, the overnight rate may contain all the relevant information for the central bank regarding market expectations for liquidity conditions and interest rates in the remainder of the maintenance period. Furthermore, while the overnight rate possibly can be affected by changing the liquidity conditions, the forward rates spanning beyond the current maintenance period may probably only be affected very indirectly by MRO allotments, if the central bank could provide credible signals about future monetary policy moves in its allotments.

For the estimation based on the EONIA spread, we find the coefficient $\beta$ to be 2.12. This implies that, say, a positive EONIA spread of 10 basis points would have led to a MRO allotment, or more specifically $E_{d}\left(\overline{E R}_{d+j}\right)$, which on average would have been around EUR 0.2 billion higher than the expected "normal" average daily demand for excess reserves $E_{d}\left(\overline{E R}^{N O R M}\right)$. Using the spot and forward interest rates with the slightly longer maturities, the coefficient $\beta$ decreases but remains positive and significant, which is a good sign for the robustness of the analysis.

Giving prominence to the results for the EONIA spread, equation (14) translates into the following simple function for the supply of liquidity in the weekly MROs (the vector of dummies is described below):

$$
\text { Policy }_{t}=2.12 s_{t-1}+\omega D_{t}
$$

We find that there has been no significant difference between the liquidity policy reaction to interest rates in the last $\mathrm{MRO}$ of the maintenance period and in the preceeding MROs. ${ }^{28}$ This may appear surprising

\footnotetext{
${ }^{27}$ Since the allotment decision is made in the morning, the most recent EONIA observation is that on the announcement day.

${ }^{28} \mathrm{We}$ omit the liquidity policy reaction in the first MROs of the maintenance period in the estimation based on the EONIA. The lagged interest rate observation associated with these MROs covers the last days of the previous maintenance period. The spike in rates which often occur on these days due to accumulated liquidity imbalances is not likely to be relevant for the MRO decision in the following maintenance
} 
since, taken from the demand equation, no effect on interest rates from deviating from a benchmark allotment should be expected in the MROs prior to the end of the maintenance period.

We find an asymmetric response to positive and negative spreads of the overnight rate over the main refinancing rate with a larger reaction to positive spreads. However, as already mentioned for the demand side, there are very few observations of a negative spread in the sample period and about half of these occurrances led to underbidding for which dummies are attached in the supply equation. ${ }^{29}$. The test was also conducted using the crude measure of the "natural" spread of 6 basis points from the demand equation (the constant) as the pivotal point instead of zero, and this confirmed the result on asymmetry. This is perhaps not surprising. EONIA spread observations between zero and 6 basis points have probably been regarded more as "on track" than a situation which should have elicited active liquidity management to spur an increase in rates. The asymmetry in the observations of the interest rates pertains to some extent to the presence of the minimum bid rate, which sets a floor to the two-week MRO tender rates. The asymmetry in tender rates within the corridor also affects rates in the secondary market. By testing the relation with quadratic terms in order to capture possible non-linearities, we find no indications that large deviations in the overnight rate from the main refinancing rate have carried a particularly high weight for the central bank. We also test for a structural break associated to the switch from fixed to variable rate tenders in June 2000, and find that there appears to have been no significant difference in the MRO allotment policy under the two tender procedures.

Furthermore, we consider the inclusion of a number of dummies controlling for extraordinary conditions which occurred during our sample period. Figure 12 shows the actual and fitted values of Policy in the main supply equation were the visible outliers are tracked by the considered dummies. The most relevant dummies seem to be related to the underbidding episodes, and in particular the no-bail-out responses from

period. By constructing an alternative EONIA spread measure, which deviates by using the average rate in the days from the start of the maintenance period until the first MRO instead of the average rate from the last days of the previous maintenance period, the liquidity policy reaction to the EONIA spread proves to be similar to the reaction in the other MROs. However, we choose to employ the original EONIA spread measure for both the demand and supply side to allow for a joint determination (the EONIA spread evolution on the last days of a maintenance period is important for the demand side of the model).

${ }^{29}$ Note that spikes in rates between the last MRO of a maintenance period and the end of the period are not considered in the EONIA spread variable relevant for the supply equation, as mentioned in the previous footnote. 


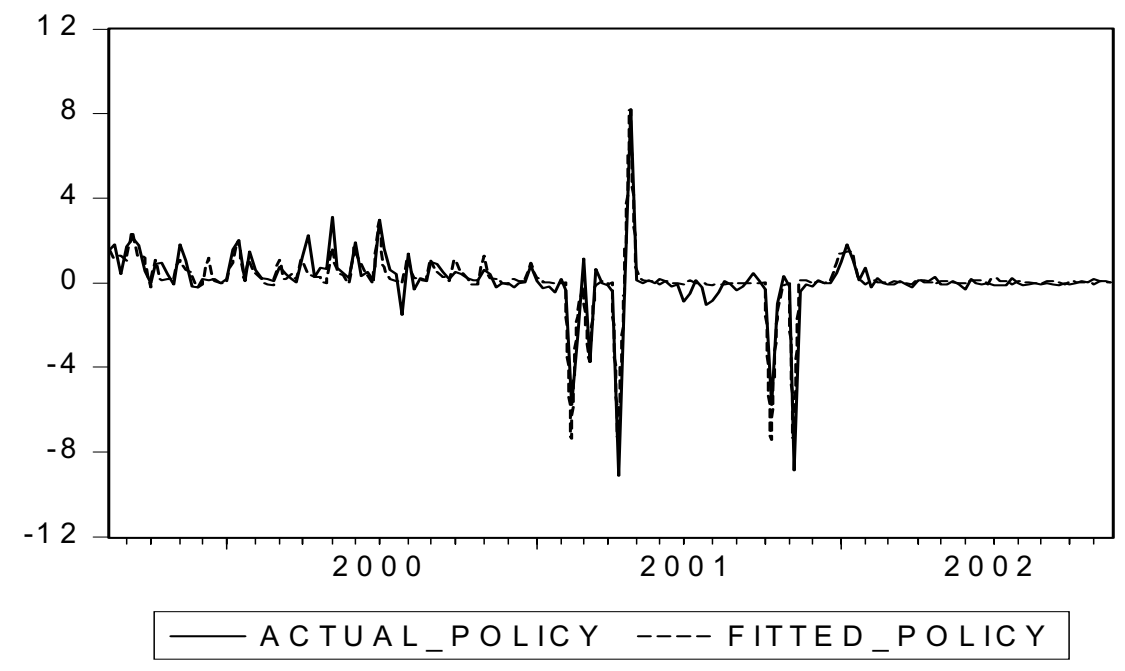

Figure 12: Actual and fitted values of policy in the main supply function

the ECB, in 2001, and two MROs in which the ECB restored the balance between the sizes of the two outstanding MROs. Also, a dummy variable controls for a period in the autumn of 1999 characterized by consistently ample liquidity provision to counter overbidding (ECB, 2002b). Furthermore, observations affected by fine-tuning operations and endof-year effects are also pinned down by dummy variables. Finally, we identify a dummy with a positive coefficient for the MROs close to the end-of-month in 1999 and 2000. This dummy may be explained by some sensitivity to tensions in the money market related to the end-of-month effects and possibly also some preference for frontloading the provision of liquidity. However, this effect appears to have been relevant only for 1999 and 2000, whereas it is found to be insignificant for 2001 and 2002. To examine the robustness of the coefficient $\beta$, the estimation is also conducted omitting completely the vector of dummies. This results in an estimate of $\beta$ of 2.06 , which is statistically indistinguishable from the coefficient of the original equation.

There are generally no problems of residual non-linearity in the estimations according to RESET tests, neither are the estimations distorted by serial correlation of the residuals. As for the demand side, we test the residuals against the explanatory variables and find support for the linear approximation. Non-Normal residuals are present, as for the demand equation, but this again seems unavoidable with high frequency data. The ARCH Lagrange multiplier test shows that the standardised residuals contain no ARCH effects. Recursive residuals and CUSUM 


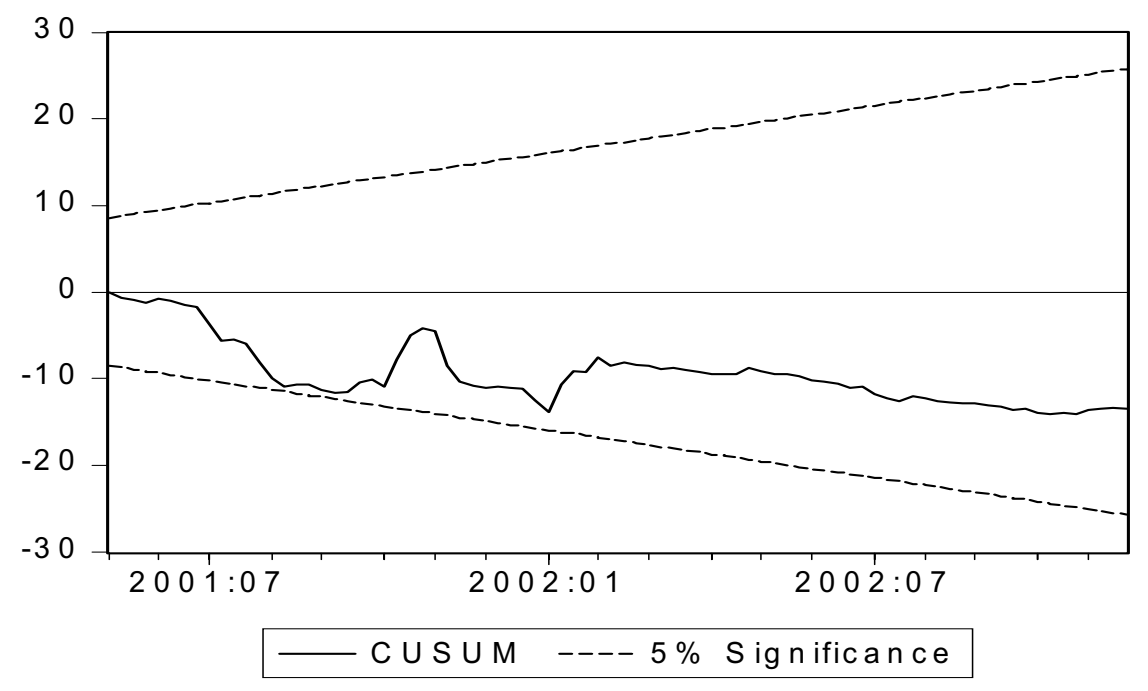

Figure 13: Recursive residuals and CUSUM tests of the main supply equation

tests are difficult to calculate due to the near-singular matrices originating from the dummies. In Figure 13, the tests are shown omitting the fine-tuning dummies to reduce the number of parameters and allow for a longer test period (April 2001 until November 2002). For this period, there are no signs of instability in the estimated equation.

\section{Discussion of the results}

The results of the previous analysis suggests a simple demand-supply characterization of the behaviour of the euro area money market, as follows:

Demand: $s_{t}=0.06+0.14 s_{t-1}-0.37 L_{t} D E N D_{t}-0.02 L_{t}\left(1-D E N D_{t}\right)$

$$
\text { Supply: } \text { Policy }_{t}=2.12 s_{t-1}+\omega D_{t}
$$

Some interesting considerations may be derived from this simple model. A main conclusion of this analysis, in particular, is that the ECB had a strong preference for providing a neutral liquidity allotment in the considered sample period. In normal conditions, this has generally implied also that the EONIA spread was close to zero, i.e. that the main refinancing rate was the actual anchor for the monetary policy stance in the euro area. However, as noted above, expectations of a change in the main refinancing rate during the maintenance period create a situation 
in which liquidity and interest rate smoothing cannot be accomplished simultaneously and a compromise between the two objectives has to be taken. Our estimates suggest that, in such cases, leaning against interest rate expectations has not played a significant role in the ECB's liquidity policy in the first four years of Stage Three of EMU. Indeed, before the last MRO of the maintenance period the reaction of liquidity policy to existing interest rate change expectations, however measured, has been far too weak to offset their impact on the EONIA spread, also considering the very small impact of liquidity imbalances onto the EONIA spread apart from the last week of the maintenance period, as estimated in the demand side of the model.

Formally, it is worth recalling that the coefficient $\beta$ in the liquidity reaction function in (14) is derived as follows (see Annex I):

$$
\beta=\frac{(1-\gamma)(1-\theta)}{\gamma+(1-\gamma) \varphi^{2}}
$$

As we find that $\theta$ is close to zero, this can be simplified to:

$$
\beta=\frac{(1-\gamma)}{\gamma+(1-\gamma) \varphi^{2}}
$$

Having estimated $\beta$ and $\varphi$, it is possible to make a back-of-theenvelope calculation of the possible size of $\gamma$ in the liquidity management loss function, and this leads to the conclusion that $\gamma$ is very close to one. For example, an upward impact of 10 basis points due to expectations of a change in the main refinancing rate later on prompted a loose liquidity allotment by EUR 0.2 billion which, taking into account the results for the demand side of the model, implies a reduction in the EONIA spread by only 0.4 basis points before the last $\mathrm{MRO}$ of the maintenance period. Theoretically, the effect on the EONIA spread would be larger in the last $\mathrm{MRO}$, but at this point of the maintenance period there were usually no interest rate change expectations prevailing anymore, due to the fact that Governing Council meetings have seldom been in the last week of the maintenance period in our sample period.

The apparently scant use of "active" liquidity policy to stabilize the EONIA around the main refinancing rate, which departs from the US Federal Reserve practice as emphasised by Taylor (2001), is consistent with a scheme between the "dealing rate model" and the "open mouth approach" (Manna, Pill and Quiros, 2001), in which the overnight rate is not a policy objective. Monetary policy signalling was in fact achieved through the main refinancing rate, and the determination of the overnight rate was left primarily to market forces. Indeed, pegging the overnight rate at all points in time to the main refinancing rate has 
not been a policy objective for the ECB. This possibly also suggests that spreads observed in the market were in line with signals provided by the ECB about its future policy. At the same time, it has to be taken into account that the liquidity reaction function that we estimate took place in an environment of generally low volatility of short-term interest rates and orderly money market trading conditions. So, the lack of a very "active" liquidity policy during the first four years of EMU might be explained not only by the ECB's preferences, but also at least in part by the conditions under which this policy was carried out. As mentioned earlier, in the absence of pronounced interest rate change expectations, interest rate and liquidity smoothing are mutually consistent objectives.

\section{Conclusions}

This paper has provided a simple weekly model of the demand and supply of liquidity in the euro area, close to the analysis by Taylor (2001) on the federal funds market in the United States. The paper reaches the following conclusions. From a demand perspective, the analysis in this paper finds that the liquidity situation appears to have mattered to a significant extent only in the last week of the maintenance period, and to have had a negligible effect earlier in the maintenance period. This finding presumably reflects both the structural features of the euro area money market, in particular the level of the reserve requirement which makes reserves void of liquidity services at the margin, and market participants' perception that the ECB's liquidity policy is neutral at the end of the maintenance period. Indeed, from the supply side of the model we find that the ECB's liquidity policy has been normally neutral. There appears to have been some reaction to deviations of the overnight rate from the main refinancing rate, but the reaction has been small on average over the sample period. Overall, liquidity smoothing can be characterized as the main objective of the ECB's liquidity policy during the first four years of EMU. One interpretation of this result may be that the operational framework of the ECB has worked satisfactorily in keeping the EONIA close to the main refinancing rate without the need for a more active liquidity policy. Furthermore, there may have been occasions where deviations of short-term rates from the then prevailing main refinancing rate emerged after the ECB signalled a monetary policy change in the future.

Our analysis is mainly descriptive and does not assess the welfare consequences of the liquidity policy which we observe. However, the analysis provides a simple framework for addressing such issues and the derivation of a liquidity policy rule which is optimal from a welfare perspective is the natural extension of this analysis. This extension might 
be aimed at dealing with fundamental issues such as the relative weight of interest rate and liquidity smoothing in the liquidity management's ideal loss function, which have been touched upon only casually in the literature and yet represent an interesting topic for research in this field. 


\section{References}

[1] Angelini, P., 2002. Liquidity and announcement effects in the euro area. Banca d'Italia Temi di Discussione n. 451, October.

[2] Ayuso, J., Repullo, R., 2000. A model of the open market operations of the European Central Bank. CEPR discussion paper no. 2605.

[3] Bartolini, L., Bertola, G., Prati, A., 2002. The overnight interbank market: Evidence from the G-7 and the euro zone. Forthcoming in Journal of Banking and Finance.

[4] Bartolini, L., G., Prati, A., 2003. The execution of monetary policy: a tale of two central banks. Paper presented at the 37th Panel Meeting of Economic Policy in Athens, March.

[5] Bindseil, U., 2002. Equilibrium bidding in the Eurosystem's open market operations. ECB Working Paper no. 137.

[6] Bindseil, U., Camba-Mendez, G., Hirsch A., Weller, B., 2003. Excess reserves and the ECB's implementation of monetary policy. Paper presented at the conference Monetary Policy and the Money Market, Federal Reserve Bank of New York, 5-6 June.

[7] Bindseil, U., Seitz, F., 2001. The supply and demand for Eurosystem deposits - the first 18 months. ECB Working Paper no. 44.

[8] Clouse, J.A., Dow, J.P., 1999. Fixed costs and the behaviour of the federal funds rate. Journal of Banking and Finance, 23, pp. 10151029 .

[9] ECB, 2001. Autonomous liquidity factors in the euro area and the use of the forecasts of liquidity needs provided by the ECB. Box in the Monthly Bulletin, July.

[10] ECB, 2002a. The single monetary policy in Stage Three: General documentation on Eurosystem monetary policy instruments and procedures. April.

[11] ECB, 2002b. The liquidity management of the ECB in the context of the operational framework of the Eurosystem. Article in the Monthly Bulletin, May.

[12] Feinman, J., 1993. Estimating the Open Market Desk's daily reaction function. Journal of Money, Credit and Banking, 25, 2, pp. 231-247.

[13] Gilchrist, S., 2001. Commentary to 'Identifying the liquidity effect at a daily frequency'. Federal Reserve Bank of St. Louis Review 83, pp. 79-83.

[14] Hamilton, J. D., 1996. The daily market for federal funds. Journal of Political Economy, 104, 1, pp. 26-56.

[15] Hamilton, J. D., 1997. Measuring the liquidity effect. American Economic Review, 87, pp. 80-97.

[16] Hartmann, P., Manna, M., Manzanares, A., 2001. The microstruc- 
ture of the euro money market. Journal of International Money and Finance, 20, 6, pp. 895-948.

[17] Manna, M., Pill, H., Quiros, G., 2001. The Eurosystem's operational framework in the context of the ECB's monetary policy strategy. International Finance, 4, 1, pp. 65-99.

[18] Moschitz, J., 2002. The interbank rate and the liquidity effect in the euro area. Working paper. Universitat Autonoma de Barcelona.

[19] Orphanides, A., 2001. Commentary to 'Expectations, open market operations, and changes in the federal funds rate'. Federal Reserve Bank of St. Louis Review, July-August, pp. 49-57.

[20] Perez Quiros, G., Mendizabal, R., 2001. The daily market for funds in Europe: has something changed with EMU?. ECB Working Paper n. 67.

[21] Taylor, J., 2001. Expectations, open market operations, and changes in the federal funds rate. Federal Reserve Bank of St. Louis Review, July-August, pp. 33-48.

[22] Thornton, D. L., 2001a. Identifying the liquidity effect at the daily frequency. Federal Reserve Bank of St. Louis, July/August, pp. 5978.

[23] Thornton, D. L., 2001b. The Federal Reserve's operating procedure, nonborrowed reserves, borrowed reserves and the liquidity effect. Journal of Banking and Finance, 25, pp. 1717-1739.

[24] Valimäki, T., 2002. Variable rate liquidity tenders. Bank of Finland Discussion Paper no. 24, September.

[25] Woodford, M., 1999. Optimal policy inertia. The Manchester School, Supplement, 67, pp. 1-35.

[26] Würtz, F. R., 2003. A comprehensive model on the euro overnight rate. ECB Working Paper no. 207. 


\section{Annex I: Derivation of the empirical linear reac- tion function in (14)}

In the setting of our model, the central bank is assumed to minimize the expected value of the loss function in (13), based on the information set available at time $t-1$, namely:

$$
E_{t-1} \text { Loss }_{t}=\gamma \text { Policy } y_{t}^{2}+E_{t-1}(1-\gamma) s_{t}^{2}
$$

Noting that, from (8) and taking into account that $E_{t-1} \varepsilon_{t}^{A F}=0$, we obtain that:

$$
E_{t-1}(1-\gamma) s_{t}^{2}=-2(1-\gamma) \text { Policy }_{t} E_{t-1}^{M} \Delta_{t, t+1} s+(1-\gamma) \varphi^{2} \text { Policy }_{t}^{2}+c,
$$

where $c$ is a term which does not depend on Policy, and the superscript $M$ indicates the expectation held by market participants, which under discretion is given for the central bank at time $t$. We assume, in fact, that the optimization is carried out under discretion, i.e. taking market expectations as given.

Therefore, we have:

$$
E_{t-1} \text { Loss }_{t}=\left[\gamma+(1-\gamma) \varphi^{2}\right] \text { Policy }_{t}^{2}-2(1-\gamma) \varphi \text { Policy }_{t} E_{t-1}^{M} \Delta_{t, t+1} s+c
$$

The first order condition for Policy is:

$$
2\left[\gamma+(1-\gamma) \varphi^{2}\right] \text { Policy }_{t}-2(1-\gamma) \varphi E_{t-1}^{M} \Delta_{t, t+1} s=0,
$$

or:

$$
\text { Policy }_{t}^{*}=\frac{(1-\gamma) \varphi}{\left[\gamma+(1-\gamma) \varphi^{2}\right]} E_{t-1}^{M} \Delta_{t, t+1} s,
$$

where the asterisk indicates the optimal value. Note that, if $\gamma=1$ (the central bank cares only about liquidity smoothing), we obtain Policy $y_{t}=$ 0 , as mentioned in the text. Conversely, if $\gamma=0$ (the central bank cares only about interest rate smoothing) we have Policy $t_{t}^{*}=\frac{1}{\varphi} E_{t-1}^{M} \Delta_{t, t+1} s$, which (from (8)) implies $E_{t-1} s_{t}=0$ at all $t$.

In equation (14) we also allow for the possibility that the reaction function may be characterized by partial adjustment, as follows:

$$
\text { Policy }_{t}=(1-\theta) \text { Policy }_{t}^{*}+\theta \text { Policy }_{t-1},
$$

where the asterisk indicates the optimal value of Policy and $\theta$ is the partial adjustment parameter (if $\theta=0$, the adjustment is complete). Calling $\beta=\frac{(1-\gamma)(1-\theta)}{\left[\gamma+(1-\gamma) \varphi^{2}\right]}$, we obtain the same reaction function as in equation (14), apart from a constant term and a vector of dummy variables. 


\section{Annex II - Chart and Tables}
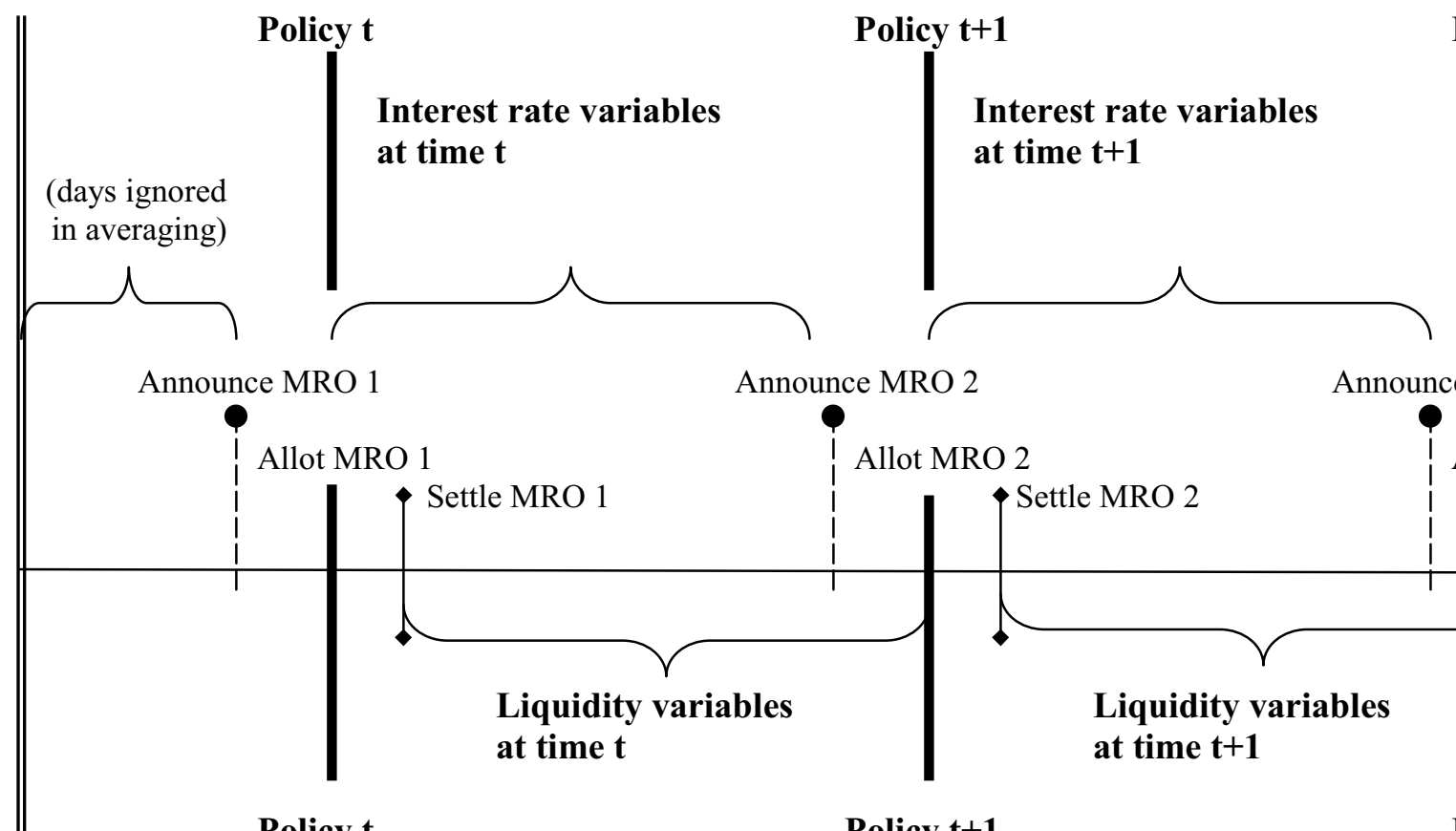

Policy t

iquidity variables

\section{at time $t$}

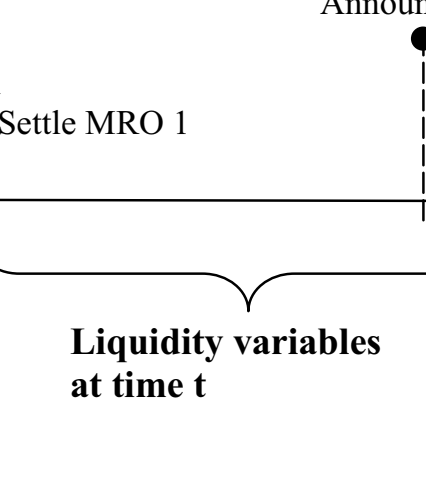

MRO 2

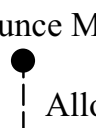

Allot MRO 2

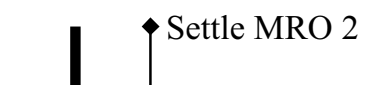

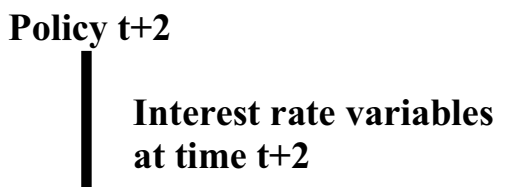

Announce MRO 3

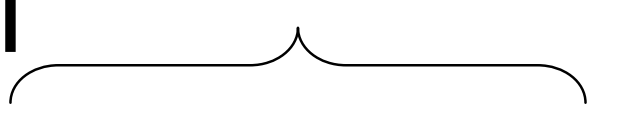

Announce MRO 4

Policy $\mathbf{t}+3$

Interest rate

variables $\mathbf{t}+\mathbf{3}$

(not used in the

supply equation)

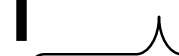

- The interest rate variables' daily observations are averaged from the allotment day to the following announcement day.

- The Policy variable shows the target daily average reserve surplus at the next allotment or the end of the maintenance period, whichever comes first, decided on the allotment day, minus the estimate of "natural" reserve surplus.

- The Liquidity variable reflects the expected daily average reserve surplus at the next allotment or the end of the maintenance period (how the policy target "evolves" reflecting the evolution of autonomous factors) minus the estimate of "natural" reserve surplus. Daily observations are averaged from the settlement day to the following allotment day. The autonomous factor shocks variable is then derived as the difference between Liquidity and Policy, on a weekly basis, excluding the use of standing facilities. 
Table 1 - OLS estimation of the demand equation using different interest rate measures; (t-statistics) and [critical values] in brackets

The dependent variable is the EONIA spread (estimation sample from 3 August 1999 to 23 November 2002)

\begin{tabular}{|c|c|c|c|}
\hline & $\begin{array}{c}\text { Lagged EONIA spread } \\
\text { "Benchmark" demand equation }\end{array}$ & $\begin{array}{l}\text { Spread between } 1 \mathrm{w} / 1 \mathrm{w} \text { forward } \\
\text { rate and the main refinancing rate }\end{array}$ & $\begin{array}{l}\text { Spread between } 1 \mathrm{~m} / 1 \mathrm{~m} \text { forward } \\
\text { rate and the main refinancing rate }\end{array}$ \\
\hline Constant & $0.06(4.98)$ & $0.06(5.24)$ & $0.06(4.86)$ \\
\hline Measure of interest rate change expectations & $0.14(2.20)$ & $0.11(1.69)$ & $0.11(2.10)$ \\
\hline Policy in the last MRO of the MP & $\begin{array}{l}-0.37(-7.63) \\
\end{array}$ & $-0.40(-8.07)$ & $-0.41(-8.20)$ \\
\hline Policy in the previous MROs to the last of the MP & $-0.02(-3.12)$ & $-0.02(-2.99)$ & $-0.02(-3.25)$ \\
\hline Autonomous factor shocks $\left(\varepsilon^{\mathrm{AF}}\right)$ in the last week of the MP & $-0.33(-3.20)$ & $-0.32(-3.03)$ & $-0.31(-2.96)$ \\
\hline R squared & 0.33 & 0.32 & 0.33 \\
\hline DW Serial correlation & 1.91 & 1.69 & 1.6 \\
\hline Autocorrelation AR 1-2 test: & $\mathrm{F}(2,164)=0.55250[0.5766]$ & $\mathrm{F}(2,164)=2.1371[0.1213]$ & $\mathrm{F}(2,164)=2.5771[0.0791]$ \\
\hline Normality test: & $\mathrm{Chi}^{\wedge} 2(2)=102.02[0.0000]^{* *}$ & $\mathrm{Chi}^{\wedge} 2(2)=123.96[0.0000]^{* *}$ & $\mathrm{Chi}^{\wedge} 2(2)=144.37[0.0000]^{* *}$ \\
\hline ARCH 1-1 test: & $\mathrm{F}(1,164)=3.3369[0.0696]$ & $\mathrm{F}(1,164)=3.4491[0.0651]$ & $\mathrm{F}(1,164)=3.5350[0.0619]$ \\
\hline
\end{tabular}


Annex II - Chart and Tables

Table 2 - OLS estimation of the "benchmark" demand equation, testing for non-equally spaced observations; (t-statistics) and [critical values] in brackets

The dependent variable is the EONIA spread (estimation sample from 3 August 1999 to 23 November 2002)

\begin{tabular}{|lcc|}
\hline Constant & $0.06(5.18)$ & $0.06(5.12)$ \\
Lagged EONIA spread & $0.13(1.99)$ & $0.13(2.00)$ \\
\hline $\begin{array}{l}\text { Liquidity situation }\left(\text { Policy }+\varepsilon^{\mathrm{AF}} \text { ) in the last MRO of the MP }\right. \\
\text { Liquidity situation }\left(\text { Policy }+\varepsilon^{\mathrm{AF}} \text { ) in the last MRO of the MP * }\right. \\
\text { the deviation in days from the average number }\end{array}$ & $\mathbf{- 0 . 3 7 ( - 8 . 0 4 )}$ & $-0.36(-7.42)$ \\
Liquidity in the previous weeks to the last in the MP & - & $-0.01(-0.38)$ \\
\hline R squared & $\mathbf{- 0 . 0 2 ( - 2 . 7 6 )}$ & $-0.02(-2.75)$ \\
DW Serial correlation & 0.32 & 0.32 \\
Autocorrelation AR 1-2 test: & $\mathrm{F}(2,166)=0.55452[0.5754]$ & 1.91 \\
Normality test: & $\mathrm{Chi} \wedge 2(2)=102.33[0.0000]^{* *}$ & $\mathrm{~F}(2,165)=0.59351[0.5536]$ \\
ARCH 1-1 test: & $\mathrm{F}(1,166)=3.8306[0.0520]$ & $\mathrm{Chi} 2(2)=107.26[0.0000]^{* *}$ \\
RESET test: & $\mathrm{F}(1,167)=3.6142[0.0590]$ & $\mathrm{F}(1,165)=3.6887[0.0565]$ \\
\hline
\end{tabular}


Annex II - Chart and Tables

Table 3 - Symmetry and sensitivity of the "benchmark" demand equation to outliers in the dataset using OLS estimation; (t-statistics) and [critical values] in brackets.

a $\quad$ The dependent variable is the EONIA spread (estimation sample from 3 August 1999 to 23 November 2002)

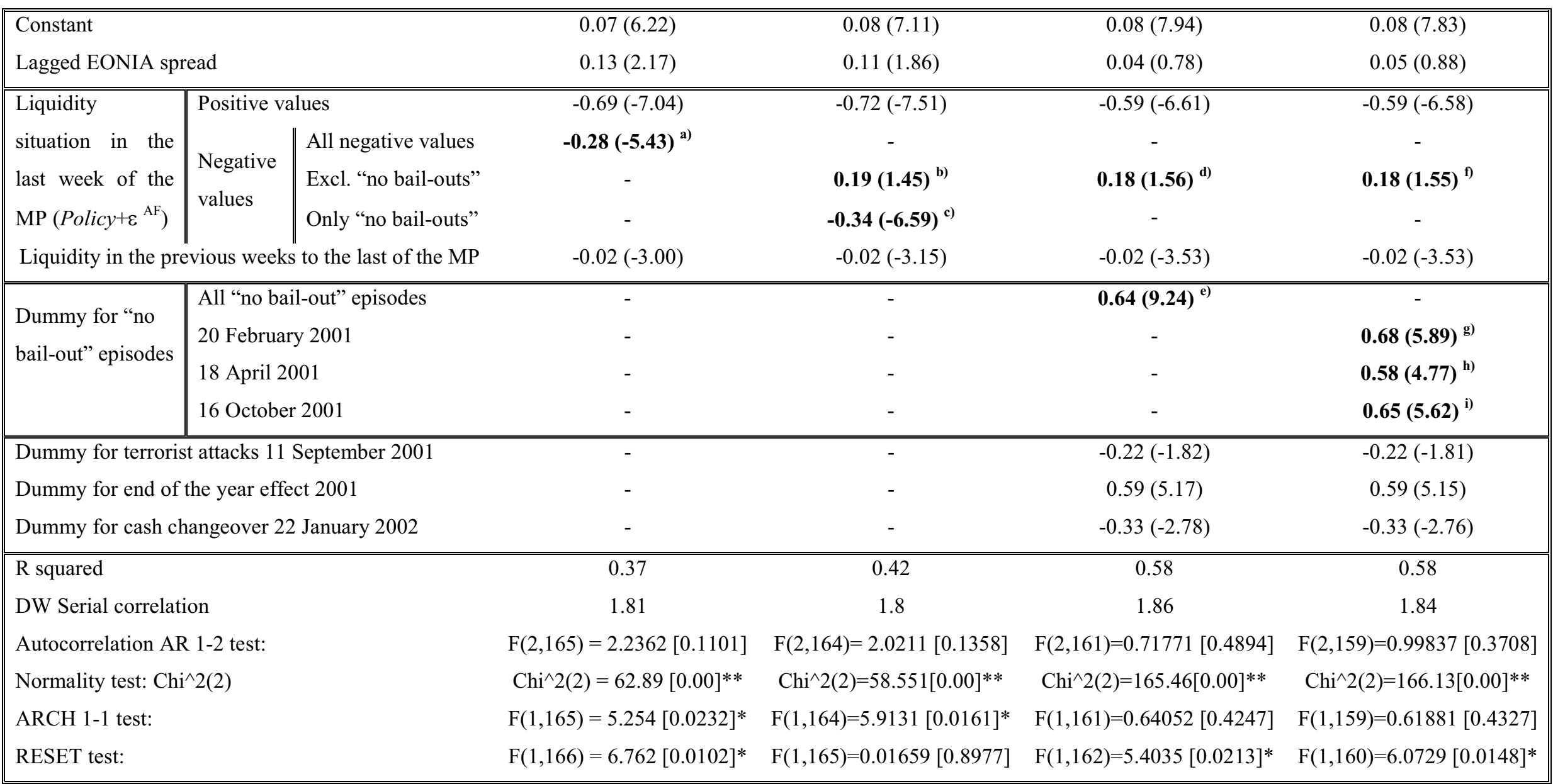

Note: In comparing coefficients, please note that a) in the first column, is comparable to the sum of b) and c) in the second column. In the third and fourth columns, the "no bail-out episodes" are accounted for by dummy variables (d) and e) and f) and g), h), and i) respectively) so that value coefficients are not strictly comparable. 
Table 4 - OLS estimation of the supply equation using different interest rate measures; (t-statistics) and [critical values] in brackets

The dependent variable is the Policy variable (estimation sample from 3 August 1999 to 23 November 2002)

\begin{tabular}{|c|c|c|c|}
\hline & $\begin{array}{l}\text { Lagged EONIA spread* } \\
\text { Main supply equation }\end{array}$ & $\begin{array}{c}\text { Spread between 2-week EONIA } \\
\text { swap and the main refinancing rate, } \\
\text { lagged }\end{array}$ & $\begin{array}{l}\text { Spread between } 1 \mathrm{~m} / 1 \mathrm{~m} \text { forward } \\
\text { and the main refinancing rate on } \\
\text { announcement day, lagged }\end{array}$ \\
\hline Constant & $-0.07(-1.39)$ & $0.00(0.00)$ & $0.01(0.21)$ \\
\hline Interest rate change expectations & $2.12(5.24)$ & $1.12(3.41)$ & $0.72(3.35)$ \\
\hline The policy variable, lagged & $0.07(2.16)$ & $0.03(0.89)$ & $0.03(0.83)$ \\
\hline Dummy for end month 1999 and 2000 & $1.14(7.91)$ & $0.97(6.13)$ & $0.98(6.17)$ \\
\hline Dummy for the loose policy period in the fall of 1999 & $1.09(5.42)$ & $1.13(5.32)$ & $1.09(5.17)$ \\
\hline Dummy for underbidding episodes & $-7.31(-28.8)$ & $-7.38(-27.9)$ & $-7.21(-26.4)$ \\
\hline Dummy for "no bail-out" episodes & $-1.66(-4.22)$ & $-1.16(-2.97)$ & $-1.02(-2.64)$ \\
\hline Dummy for MRO diverging sizes 6 March 2001 & $-4.05(-8.09)$ & $-3.83(-7.32)$ & $-3.76(-7.16)$ \\
\hline Dummy for MRO diverging sizes 24 April 2001 & $8.30(16.6)$ & $8.16(15.6)$ & $8.27(15.8)$ \\
\hline DW Serial correlation & 2.03 & 2.21 & 2.16 \\
\hline Autocorrelation AR 1-2 test: & $\mathrm{F}(2,157)=3.0143[0.0519]$ & $\mathrm{F}(2,157)=1.8549[0.1599]$ & $\mathrm{F}(2,157)=2.2531[0.1085]$ \\
\hline Normality test: & $\mathrm{Chi}^{\wedge} 2(2)=57.145[0.0000]^{* *}$ & $\mathrm{Chi}^{\wedge} 2(2)=55.685[0.0000]^{* *}$ & $\mathrm{Chi}^{\wedge} 2(2)=60.464[0.0000]^{* *}$ \\
\hline ARCH 1-1 test: & $\mathrm{F}(1,157)=0.20604[0.6505]$ & $\mathrm{F}(1,157)=0.35161[0.5541]$ & $\mathrm{F}(1,157)=0.077356[0.7813]$ \\
\hline RESET test: & $F(1,158)=1.5542[0.2144]$ & $\mathrm{F}(1,158)=0.42038[0.5177]$ & $\mathrm{F}(1,158)=5.5643[0.0196]^{*}$ \\
\hline
\end{tabular}

* The last weekly EONIA observation in the maintenance periods is omitted (using the dummy DEND). The EONIA in the last week of a maintenance period often spikes due to temporary liquidity shocks that are not relevant for the first allotment decision in the following maintenance period. 


\section{European Central Bank working paper series}

For a complete list of Working Papers published by the ECB, please visit the ECB's website (http://www.ecb.int).

202 "Aggregate loans to the euro area private sector" by A. Calza, M. Manrique and J. Sousa, January 2003.

203 "Myopic loss aversion, disappointment aversion and the equity premium puzzle" by D. Fielding and L. Stracca, January 2003.

204 "Asymmetric dynamics in the correlations of global equity and bond returns" by L. Cappiello, R.F. Engle and K. Sheppard, January 2003.

205 "Real exchange rate in an inter-temporal n-country-model with incomplete markets" by B. Mercereau, January 2003.

206 "Empirical estimates of reaction functions for the euro area" by D. Gerdesmeier and B. Roffia, January 2003.

207 "A comprehensive model on the euro overnight rate” by F. R. Würtz, January 2003.

208 "Do demographic changes affect risk premiums? Evidence from international data" by A. Ang and A. Maddaloni, January 2003.

209 “A framework for collateral risk control determination” by D. Cossin, Z. Huang, D. Aunon-Nerin and F. González, January 2003.

210 "Anticipated Ramsey reforms and the uniform taxation principle: the role of international financial markets” by S. Schmitt-Grohé and M. Uribe, January 2003.

211 "Self-control and savings" by P. Michel and J.P. Vidal, January 2003.

2I2 "Modelling the implied probability of stock market movements" by E. Glatzer and M. Scheicher, January 2003.

213 “Aggregation and euro area Phillips curves” by S. Fabiani and J. Morgan, February 2003.

2I4 "On the selection of forecasting models" by A. Inoue and L. Kilian, February 2003.

215 "Budget institutions and fiscal performance in Central and Eastern European countries" by H. Gleich, February 2003.

216 "The admission of accession countries to an enlarged monetary union: a tentative assessment” by M. Ca'Zorzi and R. A. De Santis, February 2003.

217 "The role of product market regulations in the process of structural change" by J. Messina, March 2003. 
218 "The zero-interest-rate bound and the role of the exchange rate for monetary policy in Japan" by G. Coenen and V. Wieland, March 2003.

219 "Extra-euro area manufacturing import prices and exchange rate pass-through" by B. Anderton, March 2003.

220 "The allocation of competencies in an international union: a positive analysis" by M. Ruta, April 2003.

22I "Estimating risk premia in money market rates" by A. Durré, S. Evjen and R. Pilegaard, April 2003.

222 "Inflation dynamics and subjective expectations in the United States" by K. Adam and M. Padula, April 2003.

223 "Optimal monetary policy with imperfect common knowledge" by K. Adam, April 2003.

224 "The rise of the yen vis-à-vis the ("synthetic") euro: is it supported by economic fundamentals?" by C. Osbat, R. Rüffer and B. Schnatz, April 2003.

225 "Productivity and the ("synthetic") euro-dollar exchange rate" by C. Osbat, F. Vijselaar and B. Schnatz, April 2003.

226 "The central banker as a risk manager: quantifying and forecasting inflation risks" by L. Kilian and S. Manganelli, April 2003.

227 "Monetary policy in a low pass-through environment" by T. Monacelli, April 2003.

228 "Monetary policy shocks - a nonfundamental look at the data" by M. Klaeffing, May 2003.

229 "How does the ECB target inflation?" by P. Surico, May 2003.

230 "The euro area financial system: structure, integration and policy initiatives" by P. Hartmann, A. Maddaloni and S. Manganelli, May 2003.

23I "Price stability and monetary policy effectiveness when nominal interest rates are bounded at zero" by G. Coenen, A. Orphanides and V. Wieland, May 2003.

232 "Describing the Fed's conduct with Taylor rules: is interest rate smoothing important?" by E. Castelnuovo, May 2003.

233 "The natural real rate of interest in the euro area" by N. Giammarioli and N. Valla, May 2003.

234 "Unemployment, hysteresis and transition" by M. León-Ledesma and P. McAdam, May 2003.

235 "Volatility of interest rates in the euro area: evidence from high frequency data" by N. Cassola and C. Morana, June 2003. 
236 "Swiss monetary targeting 1974-1996: the role of internal policy analysis" by G. Rich, June 2003.

237 "Growth expectations, capital flows and international risk sharing" by O. Castrén, M. Miller and R. Stiegert, June 2003.

238 "The impact of monetary union on trade prices" by R. Anderton, R. E. Baldwin and D. Taglioni, June 2003.

239 "Temporary shocks and unavoidable transitions to a high-unemployment regime" by W. J. Denhaan, June 2003.

240 "Monetary policy transmission in the euro area: any changes after EMU?" by I. Angeloni and M. Ehrmann, July 2003.

24I Maintaining price stability under free-floating: a fearless way out of the corner?" by C. Detken and V. Gaspar, July 2003.

242 "Public sector efficiency: an international comparison" by A. Afonso, L. Schuknecht and V. Tanzi, July 2003.

243 "Pass-through of external shocks to euro area inflation" by E. Hahn, July 2003.

244 "How does the ECB allot liquidity in its weekly main refinancing operations? A look at the empirical evidence" by S. Ejerskov, C. Martin Moss and L. Stracca, July 2003. 